\title{
Cloud Field Identification for Earth Radiation Budget Studies. Part II: Cloud Field Classification for the ScaRaB Radiometer
}

\author{
C. J. Stubenrauch, G. Seze, N. A. Scott, A. Chedin, M. Desbois, and R. S. Kandel \\ Laboratoire de Métérologie Dynamique du CNRS, Ecole Polytechnique, Palaiseau, France
}

(Manuscript received 9 February 1995, in final form 22 August 1995)

\begin{abstract}
Gaining a better understanding of the influence of clouds on the earth's energy budget requires a cloud classification that takes into account cloud height, thickness, and cloud cover. The radiometer ScaRaB (scanner for radiation balance), which was launched in January 1994, has two narrowband channels (0.5-0.7 and 10.5$12.5 \mu \mathrm{m})$ in addition to the two broadband channels $(0.2-4$ and $0.2-50 \mu \mathrm{m})$ necessary for earth radiation budget (ERB) measurements in order to improve cloud detection. Most automatic cloud classifications were developed with measurements of very good spatial resolution $(200 \mathrm{~m}$ to $5 \mathrm{~km}$ ). Earth radiation budget experiments (ERBE), on the other hand, work at a spatial resolution of about $50 \mathrm{~km}$ (at nadir), and therefore a cloud field classification adapted to this scale must be investigated. For this study, ScaRaB measurements are simulated by collocated Advanced Very High Resolution Radiometer (AVHRR) ERBE data. The best-suited variables for a global cloud classification are chosen using as a reference cloud types determined by an operationally working threshold algorithm applied to AVHRR measurements at a reduced spatial resolution of $4 \mathrm{~km}$ over the North Atlantic. Cloud field types are then classified by an algorithm based on the dynamic clustering method. More recently, the authors have carried out a global cloud field identification using cloud parameters extracted by the 31 (improved initialization inversion) algorithm, from High-Resolution Infrared Sounder (HIRS) - Microwave Sounding Unit (MSU) data. This enables the authors first to determine mean values of the variables best suited for cloud field classification and then to use a maximum-likelihood method for the classification. The authors find that a classification of cloud fields is still possible at a spatial resolution of ERB measurements. Roughly, one can distinguish three cloud heights and two effective cloud amounts (combination of cloud emissivity and cloud cover). However, only by combining flux measurements (ERBE) with cloud field classifications from sounding instruments (HIRS/MSU) can differences in radiative behavior of specific cloud fields be evaluated accurately.
\end{abstract}

\section{Introduction}

Clouds have an important impact on the energy budget of the earth in two ways: 1 ) by limiting the absorption of solar radiation (increasing the albedo), which has a cooling effect, and 2) by partially preventing the earth-emitted thermal longwave radiation from escaping to space, which has a heating effect. The net effect on the energy budget depends upon the height, type, and location of the clouds. The influence of clouds on the present climate may be described by the term "cloud radiative forcing" (Coakley and Baldwin 1984; Charlock and Ramanathan 1985) or more correctly "cloud-induced radiative flux change" (CRFC), which is defined as the difference between the mean flux of a region and the mean flux under clear sky of the same region. From 1984 to 1990, the Earth Radiation Budget Experiment (ERBE) mission, a series of scanning and wide-field-of-view radiometers on the intermediate inclination satellite ERBS (earth radia-

Corresponding author address: Dr. Claudia J. Stubenrauch, Laboratoire de Météorologie Dynamique du CNRS, Ecole Polytechnique, F-91128 Palaiseau, Cedex, France. tion budget satellite) and on the polar-orbiting satellites $N O A A-9$ and NOAA-10, provided measurements of the earth radiation budget (ERB). From these data, Harrison et al. (1990) evaluated the annual global mean CRFC as $-17 \mathrm{~W} \mathrm{~m}^{-2}$, corresponding to an overall cooling effect of clouds. Most global circulation models (GCMs) yield the same qualitative conclusion, but the actual value of the CRFC varies widely (Cess et al. 1990), depending on how the clouds are represented in these models.

As a tool of GCM validation, cloud-induced radiative flux change has the advantage of distinguishing radiative effects of clouds from those of the clear atmosphere temperature and humidity distributions. Thus, it was shown (Cess et al. 1990) that much (but not all) of the range of climate sensitivity of different GCMs can be linked to differences in cloud radiative feedback in these models. However, even with "tuning," the success of GCMs in representing cloud distribution in the present climate depends very much upon cloud type; in particular, many GCMs still have difficulties in correctly simulating boundary layer clouds (e.g., Slingo and Slingo 1991). It is therefore desirable to refine the concept of cloud-induced radiative flux change by distinguishing different cloud field 
classes according to height, type, and coverage in order to compare in more detail the radiative effects of the different cloud types (e.g., stratiform versus convective) as they are parameterized in GCMs. Of course on the observational side, where the usual CRFC requires only the discrimination of cloud-free areas, such differentiation requires characterization of the different cloud fields together with discrimination of the corresponding radiative fluxes. Nethertheless, such a refinement is needed in order to examine the cloud radiative effects on the large-scale dynamics in the models. Furthermore, improved evaluation of cloud-radiation feedback in the models is possible only by improving each and every cloud parameterization and not by tuning a parameter in which the different classes are mixed.

The ERBE cloud scene identification (Wielicki and Green 1989) is based on a maximum-likelihood method using shortwave (SW) and longwave (LW) broadband radiances during the day and $\mathrm{LW}$ measurements alone during night. This identification yields four classes of cloud cover: clear sky $(<5 \%)$, partly cloudy (5\%$50 \%)$, mostly cloudy $(50 \%-95 \%)$, and overcast $(>95 \%)$, without distinction of cloud height and type. A more detailed cloud classification can be obtained only by combining ERBE data with additional measurements.

Narrowband visible (VIS) and infrared (IR) atmospheric window radiance measurements should improve cloud identification, since these radiances are relatively insensitive to atmospheric absorption/emission and hence give a better contrast between clouds and surface. For this reason, the radiometer $\mathrm{ScaRaB}$ ( scanner for radiation balance) (Monge et al. 1991) has been developed with two narrowband channels (VIS 0.5-0.7 $\mu \mathrm{m}$, IR 10.5-12.5 $\mu \mathrm{m}$ ) in addition to the two broadband channels (total $0.2-$ $50 \mu \mathrm{m}, \mathrm{SW} 0.2-4 \mu \mathrm{m}$ ) needed for ERB determination. Similarly, the CERES (Clouds and the Earth's Radiant Energy System) radiometer (Barkstrom 1990) has been designed with one auxiliary channel $(8-12 \mu \mathrm{m})$ in the IR atmospheric window.

Optimal cloud classification requires a relatively fine spatial resolution. This would imply treating a huge amount of data, especially if one wants to study the whole globe. There have been several studies on cloud detection and classification based on different methods: threshold algorithm (Rossow et al. 1985; Kriebel and Saunders 1988; Derrien et al. 1990; Stowe et al. 1991; Rossow and Garder 1993), dynamic clustering (Sèze and Desbois 1987), spatial and temporal coherence (Coakley and Bretherton 1982), maximum likelihood (Berger 1992), etc. However, all these algorithms were developed for a spatial resolution of about $10 \mathrm{~km}$ or finer, with most of them over limited geographical regions. Another approach takes into account information of a wider spectral range with good spectral resolution (up to 24 channels) but on a coarser spatial resolution of about $100 \mathrm{~km}$, as in the case of HIRS (High Resolution Infrared Sounder)-MSU (Micro- wave Sounding Unit) measurements (Wahiche et al. 1986; Susskind et al. 1987; Wylie and Menzel 1989).

The present analysis treats cloud field classification at a spatial resolution of about $50 \mathrm{~km}$ (at nadir), which is provided by some of the instruments used for ERB studies. After a description of the data in section 2 , the Advanced Very High Resolution Radiometer (AVHRR) cloud detection and cloud-type determination over the North Atlantic and extension to AVHRR cloud field types at ERBE resolution are described in section 3 . In section 4 , the properties of these different cloud field types are analyzed. After having chosen the most significant measurable quantities for cloud field classification, cloud field types are determined by the dynamical clustering method in section 5. Since the thresholds of the AVHRR cloud detection and classification have to be adapted for each geographic region, we use in section 6 for further reference another cloud field classification, obtained from HIRS-MSU data by applying the improved $3 I$ (improved initialization inversion) cloud algorithm (Stubenrauch et al. 1996). This cloud field classification can be applied on a global scale. Section 7 presents the analysis of cloud influence on outgoing LW fluxes for the different cloud field types. In section 8 , the mean values of the chosen variables for cloud field classification are shown for $113 \mathrm{I}$ cloud field types over the North Atlantic and the tropical Atlantic. Using these mean values of the different 3 I cloud fields as initial values of cloud cluster kernels leads to a ScaRaB cloud field identification based on a maximum-likelihood estimate (MLE) method. Clustering methods or MLE methods are more appropriate at this coarse resolution than are threshold methods. Conclusions and outlook are presented in section 9.

\section{Data}

The various channels of the three ERB instruments and of the instruments used for cloud classification in this analysis are listed in Table 1.

For this study, ERBE S8 data (Barkstrom et al. 1989) were first combined (Stubenrauch 1993) with simultaneous measurements from the AVHRR instrument in the (global area coverage) format. In this format, the spatial resolution is degraded to $4 \mathrm{~km}$, because four AVHRR pixels of $1-\mathrm{km}$ resolution are averaged, and only every fourth scan line is taken. These collocated AVHRR-ERBE data 1) simulate ScaRaB data and 2) provide more detailed information inside an ERBE pixel, given that about $150 \mathrm{GAC}$ pixels are included in an ERBE pixel.

Data were analyzed in a North Atlantic region extending from $40^{\circ} \mathrm{W}$ to $10^{\circ} \mathrm{E}$ and from $25^{\circ}$ to $65^{\circ} \mathrm{N}$ and in a tropical Atlantic region extending from $50^{\circ} \mathrm{W}$ to the Greenwich meridian and from $15^{\circ} \mathrm{S}$ to $25^{\circ} \mathrm{N}$ over six days in January 1986 and April, July, and October 1985. These data come from the National Aeronautics and Space Administration (NASA) ERBE V5 validation dataset, which 
TABLE 1. Channel description of ERB instruments and of instruments used for cloud classification.

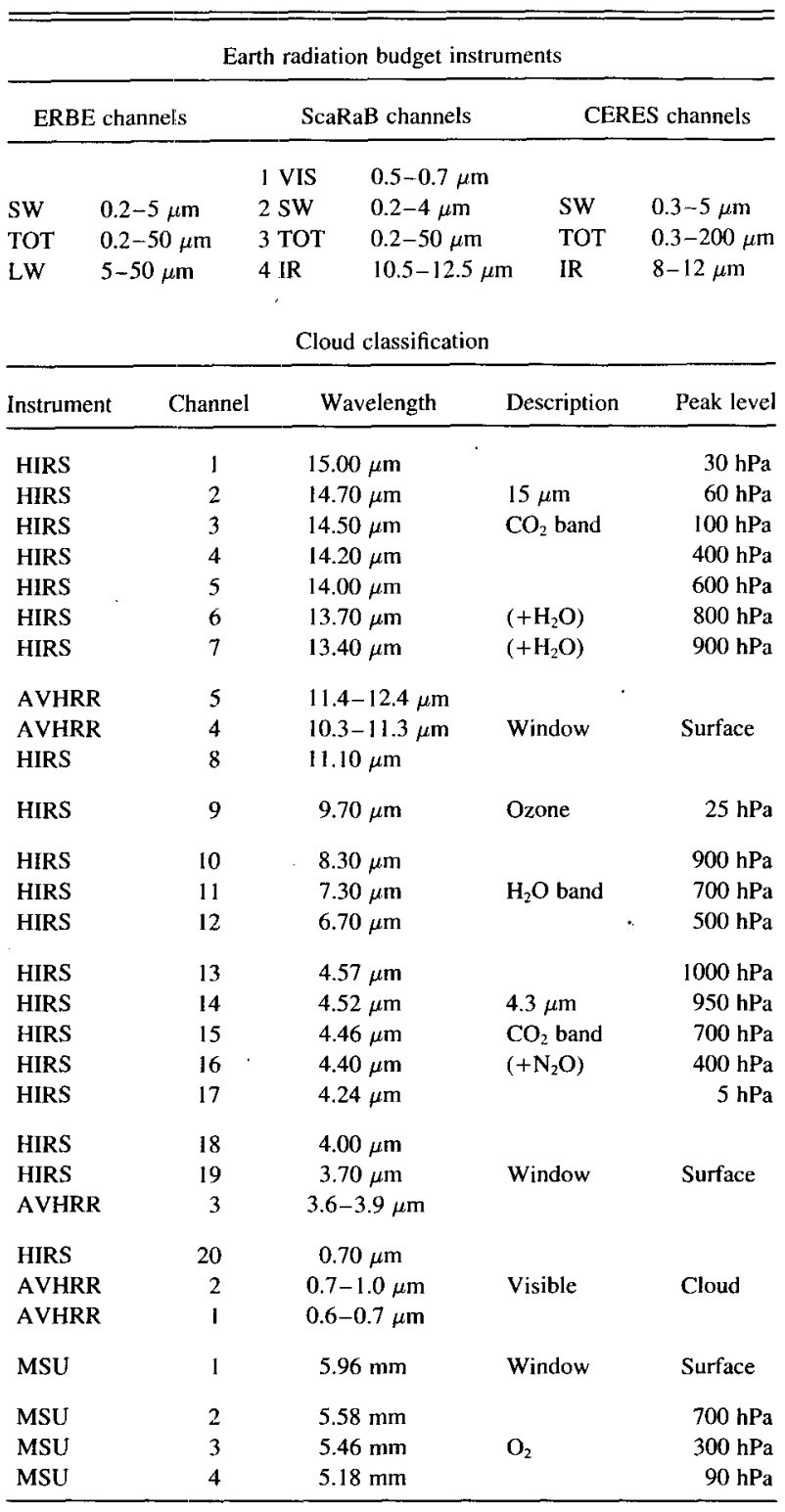

is a set of ERBE, AVHRR, and HIRS obtained simultaneously aboard NOAA-9 for different geographical regions. This dataset was distributed to ERBE science team members upon request. The measured radiances of AVHRR data were transformed into brightness temperatures using NOAA-9 calibration factors. An additional nonlinearity correction had to be applied, which is shown in tables for NOAA-9 data (Derrien 1991).

Up to this point, our efforts have been concentrated on nighttime measurements, because it is particularly during night that the ERBE algorithm-using a single variable (LW) - has to be improved.

For two night passes in July 1985 and two in January 1986, the AVHRR-ERBE data were collocated with
HIRS-MSU data at a resolution of $100 \mathrm{~km} \times 100 \mathrm{~km}$ boxes (Stubenrauch 1993), the latter including the results of the temperature inversion and cloud parameter determination by the 3I algorithm. The HIRS radiometer measured 19 IR radiances and 1 visible radiance at a spatial resolution of $18 \mathrm{~km}$ at nadir, whereas four microwave radiances are measured by the MSU instrument at a spatial resolution of about $100 \mathrm{~km}$ at nadir.

\section{AVHRR cloud detection and classification}

Below, we describe cloud detection and cloud-type classification at the scale of GAC pixels. Cloud field types are then defined at the scale of ERBE pixels, taking into account AVHRR cloud type as well as GAC cloud coverage over an ERBE pixel.

\section{a. Cloud detection at GAC resolution}

We followed the general lines of the threshold algorithm initially developed for $1-\mathrm{km}$ resolution AVHRR data by Derrien et al. (1993). These thresholds were chosen for the AVHRR data available at the receiving station of Lannion, France, that is, for an area covering the North Atlantic and Europe. This algorithm works operationally on NOAA-11 data, but other thresholds have to be developed for other geographical regions.

During night, radiance measurements at $3.7 \mu \mathrm{m}$ (channel 3), $11 \mu \mathrm{m}$ (channel 4), and $12 \mu \mathrm{m}$ (channel 5) are used. A succession of four tests, based on IR brightness temperature and emissivity differences at these wavelengths, leads to the determination of whether a pixel is clear or cloudy.

If a cloud is present, the IR brightness temperature of the pixel should be lower than the 1000-hPa temperature obtained by an analysis of the European Centre for Medium-Range Weather Forecasts (ECMWF) at 0000 UTC of the same day (Bengtsson 1991). These temperatures are available on a grid of $2.5^{\circ} \times 2.5^{\circ}$ spatial resolution, and during night they are close to the sea surface air temperature. The AVHRR IR brightness temperature was corrected for limb darkening due to atmospheric absorption. This angular correction was parameterized as a function of viewing zenith angle and pseudoabsorptance (Stubenrauch et al. 1993, their section 4) using the LOWTRAN7 radiative transfer model (Kneizys et al. 1988).

The brightness temperature of low opaque clouds containing water droplets appears higher at $11 \mu \mathrm{m}$ than at $3.7 \mu \mathrm{m}$. If their optical thickness is not too high, ice clouds can be distinguished from water clouds, because the emissivity of ice is higher at $11 \mu \mathrm{m}$ than at $12 \mu \mathrm{m}$, which leads to a higher 11- $\mu \mathrm{m}$ brightness temperature. The emissivity of water, however, does not change much between 11 and $12 \mu \mathrm{m}$. Henceforth, "cirrus clouds" will mean ice clouds that are not as thick as cumulonimbus (Rossow and Schiffer 1991). Table 2 summarizes the cloud detection tests, and only one is needed to raise the cloudy flag. 
TABLE 2. AVHRR cloud detection over ocean during night.

1. RST $[T(11 \mu \mathrm{m}), T(12 \mu \mathrm{m}), \cos \theta]<T(1000 \mathrm{hPa})-3 \mathrm{~K}$

2. $T(11 \mu \mathrm{m})-T(3.7 \mu \mathrm{m})>1.5 \mathrm{~K}$

3. $T(3.7 \mu \mathrm{m})-T(12 \mu \mathrm{m})>3 \mathrm{~K}$ for $T(11 \mu \mathrm{m})>243 \mathrm{~K}$

4. $T(11 \mu \mathrm{m})-T(12 \mu \mathrm{m})>\operatorname{Thr}[T(11 \mu \mathrm{m}), \theta]$

Retrieved surface temperature: RST $=c_{0}(\alpha)+c_{1}(\alpha) T(11 \mu \mathrm{m})$ $+c_{2}(\alpha) T(12 \mu \mathrm{m}) ; c_{0}, c_{1}$ and $c_{2}$ are given in tables for North Atlantic profiles (Llewellyn-Jones et al. 1984) and have been fitted as a function of the airmass $\alpha=1 / \cos \theta: c_{0}=-12.08(\alpha-1.30)^{2}+0.57, c_{1}$ $=-0.71(\alpha-1.67)^{2}+2.99, c_{2}=0.76(\alpha-1.65)^{2}-1.98$.

Temperature and viewing zenith angle dependent $T(11 \mu \mathrm{m})-T(12$ $\mu \mathrm{m})$ threshold: $\operatorname{Thr}[T(11 \mu \mathrm{m}), \theta]=(0.6+0.2865 \theta+0.0382 \max [0$, $T(11 \mu \mathrm{m})-264 \mathrm{~K}]$, for $T(11 \mu \mathrm{m})<298 \mathrm{~K} ;(1.9+0.2865 \theta)$ for $T(11 \mu \mathrm{m})>298 \mathrm{~K}$

\section{b. Cloud-type determination at GAC resolution}

Cloudy GAC pixels are classified according to cloud height by using $T(11 \mu \mathrm{m})$, as shown in Table 3 . Cirrus clouds are identified by a positive $T(11 \mu \mathrm{m})-T(12$ $\mu \mathrm{m})$ difference. Low opaque clouds are separated from cloud edges by a positive $T(11 \mu \mathrm{m})-T(3.7 \mu \mathrm{m})$ difference.

In the original algorithm (Derrien et al. 1993), the difference $T(3.7 \mu \mathrm{m})-T(12 \mu \mathrm{m})$ was used to distinguish between opaque and semitransparent clouds, but since this variable depends on both semitransparence and cloud height, the $T(11 \mu \mathrm{m})-T(12 \mu \mathrm{m})$ difference seems to be more appropriate, as can be seen in Fig. 1.

\section{c. Toward a cloud field identification at ERBE resolution}

By considering both cloud type and cloud cover, one can extend the nine AVHRR cloud types (Table 3) toward 18 AVHRR cloud fields at ERBE resolution: 9 overcast cloud fields (GAC pixel cloud coverage greater than $80 \%$ ) and 9 partly cloudy fields (coverage less than $80 \%$ ). However, in the studied regions, one observes that only clouds of low height appear partly cloudy, whereas high and midlevel clouds appear mostly overcast. Therefore, only 14 cloud fields are treated. An ERBE pixel is assigned to one of those fields by 1 ) its GAC cloud cover and 2) the AVHRR cloud type with highest occurrence inside the ERBE pixel.

Furthermore, for better distinction of clear sky from partly cloudy scenes at the ERBE pixel scale, we consider the $T(11 \mu \mathrm{m})$ variance of all GAC pixels inside the whole ERBE pixel: clear sky is identified when the GAC cloud cover over an ERBE pixel is less than 5\% and the $T(11 \mu \mathrm{m})$ variance is less than $2^{\circ}$. The spatial coherence test initially used on $3 \times 3$ AVHRR pixels to detect heterogeneous, and thus cloudy, regions is less significant on GAC data.

An AVHRR near-infrared region (NIR) $(3.7 \mu \mathrm{m})$ image of the meteorological situation on January 1986 is presented in Fig. 2. West of Great Britain, one can see a high opaque overcast cloud field surrounded by cirrus clouds and overcast low clouds in the south with partly cloudy low clouds in the east. A cumulus field is located east of Great Britain. Figure 3a shows the cloud cover obtained by the maximum likelihood estimation from the ERBE data. The cloud cover obtained from the GAC pixels (Fig. 3b) is more structured than that obtained directly from ERBE pixels. This is due to the better spatial resolution and to additional spectral information available in AVHRR data. ERBE detects the perturbation zones well but has difficulties in detecting low clouds and clear scenes during night. The AVHRR cloud type with the highest occurrence inside an ERBE pixel is presented in Fig. 3c, which strongly agrees with the cloud types seen in the AVHRR image.

Further comparisons of AVHRR cloud types with 3I cloud fields obtained by HIRS/MSU measurements are discussed in section 6 ( see also Stubenrauch et al. 1996, their section 4).

\section{Investigating variables for cloud field classification in comparison to AVHRR cloud fields}

In this section, the behavior of various measurable quantities is studied for the 14 AVHRR cloud fields in order to choose the most appropriate for cloud field classification with ScaRaB.

- The IR brightness temperature is often used for cloud detection and cloud height determination. Figure 4a represents the IR brightness temperature $T_{\mathrm{IR}}$ as it is measured by ScaRaB [ the mean of $T(11 \mu \mathrm{m})$ and $T(12$ $\mu \mathrm{m})$ over an ERBE pixel] as a function of latitude for clear-sky situations. It can be seen that $T_{\mathrm{IR}}$ depends strongly on the latitude. This is also the case for partly cloudy fields (not shown in Fig. 4). To find a variable independent of latitude, we introduce the surface air temperature $T_{\text {surf }}$, which can be obtained from the surface elevation $z_{\text {surf }}$, the ECMWF geopotential height at $1000 \mathrm{hPa}$, and the air temperatures at 1000,850 , and $700 \mathrm{hPa}$ as follows:

$$
p_{\text {surf }}=1000 \exp \left[-\frac{\left(z_{\text {surf }}-Z_{1000 \mathrm{hPa}}\right)}{8150 \mathrm{~m}}\right]
$$

$$
\begin{aligned}
& T_{\text {surf }}= T_{1000 \mathrm{hPa}} \frac{\left(p_{\text {surf }}-850 \mathrm{hPa}\right)}{150 \mathrm{hPa}} \\
&+T_{850 \mathrm{hPa}} \frac{\left(1000 \mathrm{hPa}-p_{\text {surf }}\right)}{150 \mathrm{hPa}}, \quad p_{\text {surf }}>850 \mathrm{hPa} \\
& T_{\text {surf }}= T_{850 \mathrm{hPa}} \frac{\left(p_{\text {surf }}-700 \mathrm{hPa}\right)}{150 \mathrm{hPa}} \\
&+T_{700 \mathrm{hPa}} \frac{\left(850 \mathrm{hPa}-p_{\text {surf }}\right)}{150 \mathrm{hPa}}, \\
& 700 \mathrm{hPa}<p_{\text {surf }}<850 \mathrm{hPa} .
\end{aligned}
$$


TABLE 3. AVHRR cloud classification during night due to height and opacity.

\begin{tabular}{lcc}
\hline \hline & & Cloud opacity \\
\cline { 2 - 3 } \multicolumn{1}{c}{ Cloud height } & $T(11 \mu \mathrm{m})-T(12 \mu \mathrm{m})<T h r[T(11 \mu \mathrm{m}), \theta]$ & $T(11 \mu \mathrm{m})-T(12 \mu \mathrm{m})>\mathrm{Thr}[T(11 \mu \mathrm{m}), \theta]$ \\
\hline$T(11 \mu \mathrm{m})<243 \mathrm{~K}$ & Cumolonimbus & Cold cirrus \\
$243 \mathrm{~K}<T(11 \mu \mathrm{m})<257 \mathrm{~K}$ & Altostratus, altocumulus & Medium cirrus \\
$257 \mathrm{~K}<T(11 \mu \mathrm{m})<267 \mathrm{~K}$ & Cumulus, stratocumulus & Thin cirrus \\
$267 \mathrm{~K}<T(11 \mu \mathrm{m})$ & $T(11 \mu \mathrm{m})-T(3.7 \mu \mathrm{m}) \quad T(11 \mu \mathrm{m})-T(3.7 \mu \mathrm{m})$ & Warm cirrus \\
& $>1.5 \mathrm{~K}$ stratus $<1.5 \mathrm{~K}$ cloud edges & $<$ \\
\hline
\end{tabular}

In Fig. 4b we study the difference $T_{\mathrm{IR}}-T_{\text {surf }}$ as a function of latitude. Since $T_{\mathrm{IR}}-T_{\text {surf }}$ shows a flat behavior, it seems to be a better variable for cloud field classification. The scattering of about $5 \mathrm{~K}$ may be explained by the different spatial resolutions of the data (about $50 \mathrm{~km}$ for $T_{\mathrm{IR}}$ and $250 \mathrm{~km}$ for $T_{\text {surf }}$ ).

- Many cloudy scenes, such as partly cloudy or high cloud scenes, are more heterogeneous in temperature than clear-sky regions (Rossow and Garder 1993). A measure of this heterogeneity can be the IR temperature variance around a pixel. Figure 5 shows the spatial resolution effect on the IR temperature variance. Figure 5 a shows $\sigma_{3 \times 3 \mathrm{GAC}}$, the $T(11 \mu \mathrm{m})$ variance of a GAC pixel and its eight nearest neighbors for the nine AVHRR cloud types, and Fig. 5 b shows $\sigma_{3 \times 3 E R B E}$, the IR temperature variance of one ERBE pixel and its eight nearest neighbors. In both figures the average values are shown with their standard deviations. About 50000 data points at ERBE resolution are used for the analysis. For the individual cloud types, the number of data points varies from 1200 to 10000 . It should be noticed that even given ERBE pixels at a scale of 3 $\times 3$ the information on heterogeneity is not lost, because the horizontal extent of many cloud fields is of the order of $50-100 \mathrm{~km}$. Overcast stratus clouds and clear sky show a very small IR temperature variance. The IR temperature variance is slightly more enhanced
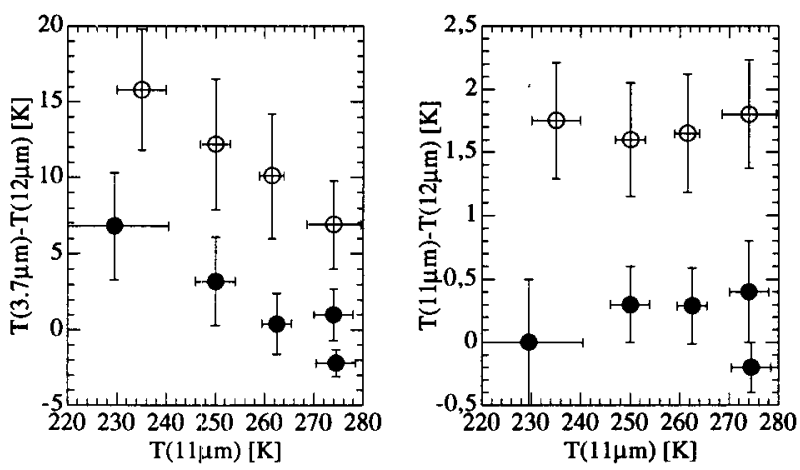

FIG. 1. Distinction between cirrus clouds (open dots) and opaque clouds (plain dots). A two-dimensional plot of (a) $T(3.7 \mu \mathrm{m})-T(12$ $\mu \mathrm{m})$ and $T(11 \mu \mathrm{m})$ for the nine classified AVHRR cloud types in Table 3 and (b) $T(11 \mu \mathrm{m})-T(12 \mu \mathrm{m})$ and $T(11 \mu \mathrm{m})$ for the nine classified AVHRR cloud types in Table 3. for cirrus clouds than for opaque clouds, because cirrus clouds vary more in optical thickness.

The IR temperature variance is smaller for a broken low-level cloud field than for a high-level cloud field with the same brokenness, because the contrast between cloud and surface is smaller. To obtain a cloud-height-independent variable, one has to minimize the temperature dependency of $\sigma_{3 \times 3 \mathrm{ERBE}}$. This was achieved by using the quantity $0.01 T_{\mathrm{IR}} \ln (1$ $+\sigma_{3 \times 3 \text { ERBE}}$ ), shown in Fig. 5c.

Some cloud detecting algorithms use the directly measured IR radiance instead of the IR temperature, because the radiance distinguishes slightly more between different warm scenes than does the temperature. However, when using IR radiance, one has to find surface radiances as a reference, which is more complicated. A scaling for the IR radiance variance must still be used, because the slightly higher sensitivity for warm scenes only partly makes up for the scaling.

- AVHRR takes advantage of different emissivities of ice and water clouds between the $12-\mu \mathrm{m}$ region and the 11- $\mu \mathrm{m}$ region. Figure 6 shows the averaged $T(11$ $\mu \mathrm{m})-T(12 \mu \mathrm{m})$ difference with its variance for the 14 AVHRR cloud field types at ERBE resolution. A significant separation of cirrus clouds from opaque ones among the 9 overcast AVHRR cloud field types is still observed. This leads to the conclusion that one can detect cirrus clouds well even at ERBE resolution. While the magnitude of this separation $(1.5 \mathrm{~K})$ may seem small, it is larger than the $T(11 \mu \mathrm{m})-T(12 \mu \mathrm{m})$ variance within the cloud types and does not depend on the calibration of the $T(11 \mu \mathrm{m})$ and $T(12 \mu \mathrm{m})$ channels. The four partially covered AVHRR cloud fields are more difficult to distinguish.

- If one wants to study different cloud radiative effects with the ScaRaB radiometer, other variables that could separate the cirrus from opaque clouds must be investigated, since ScaRaB does not measure the $T(11$ $\mu \mathrm{m})-T(12 \mu \mathrm{m})$ difference. In earth radiation budget experiments the broadband $\mathrm{LW}$ radiance is measured. One can try to combine this information with the narrowband IR radiance to define a new variable and study its behavior for the different cloud classes.

Inside the IR window, only a small amount of radiation is absorbed by the atmosphere, essentially by the water vapor continuum. Thus, from the IR brightness 


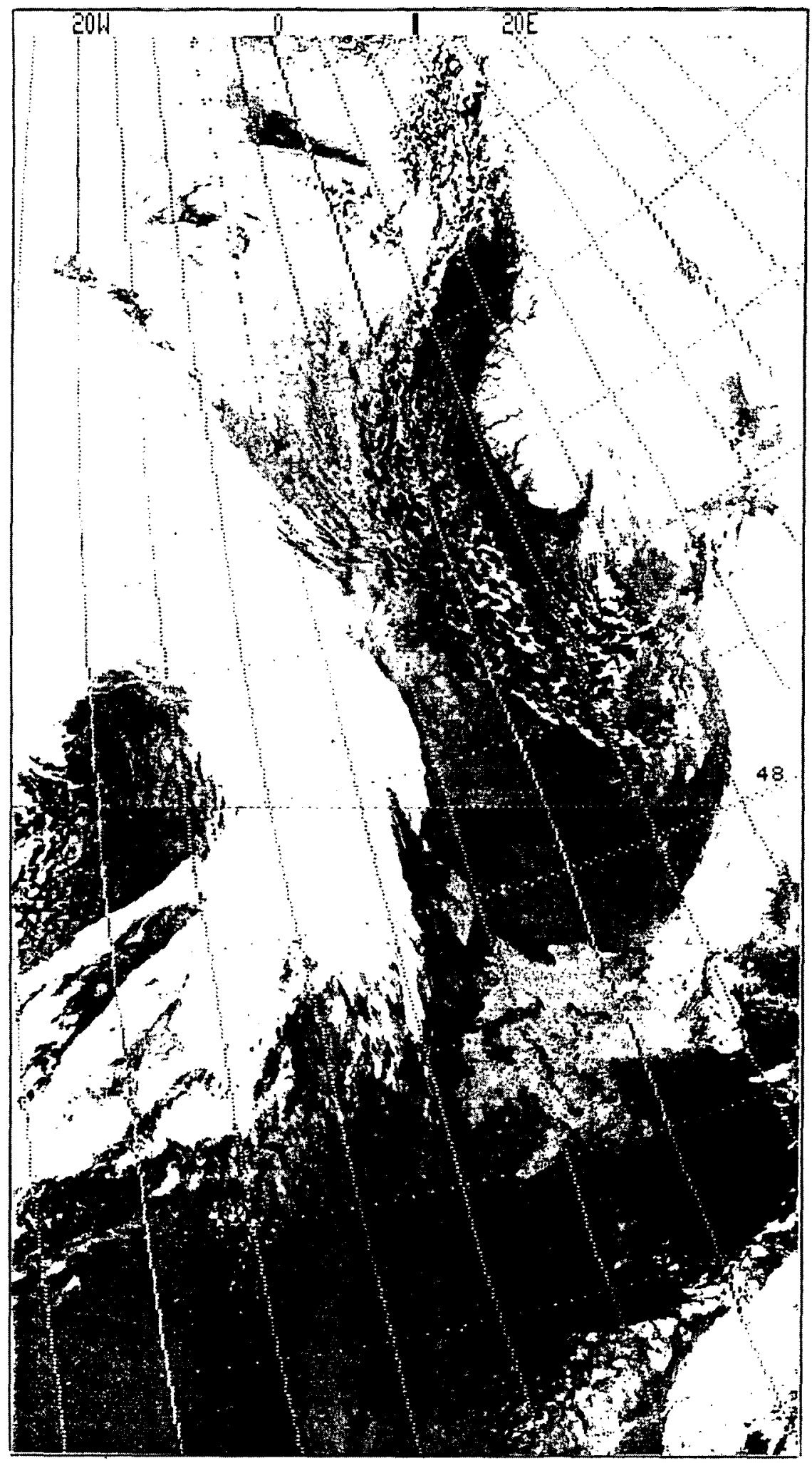

FIG. 2. AVHRR 3.7- $\mu \mathrm{m}$ image of a meteorological situation over the North Atlantic, 0330 UTC 4 January 1986 , with a longitude-latitude grid of $4^{\circ}$ resolution. 


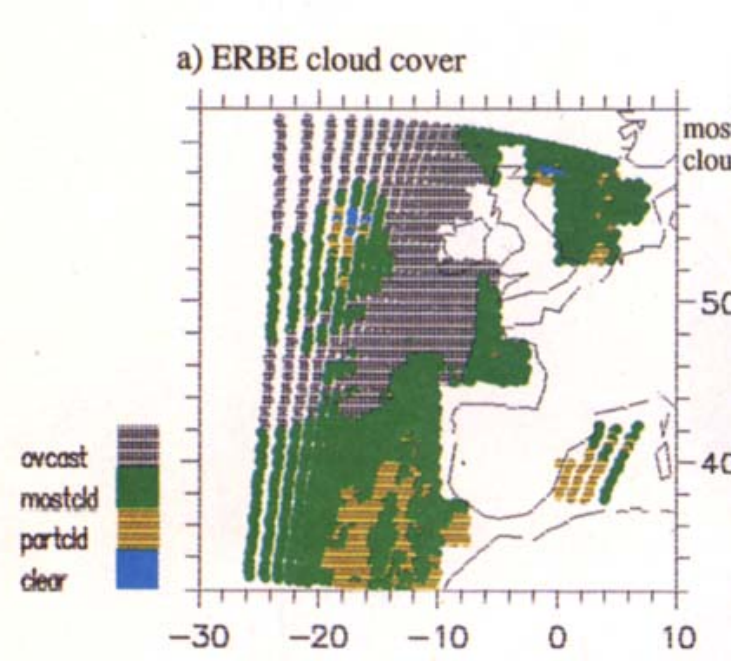

b) GAC cloud cover

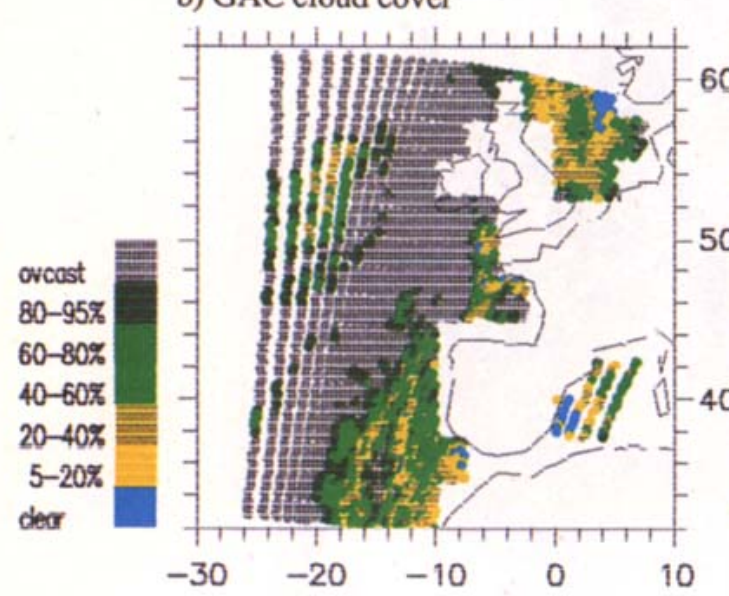

c) AVHRR cloud type

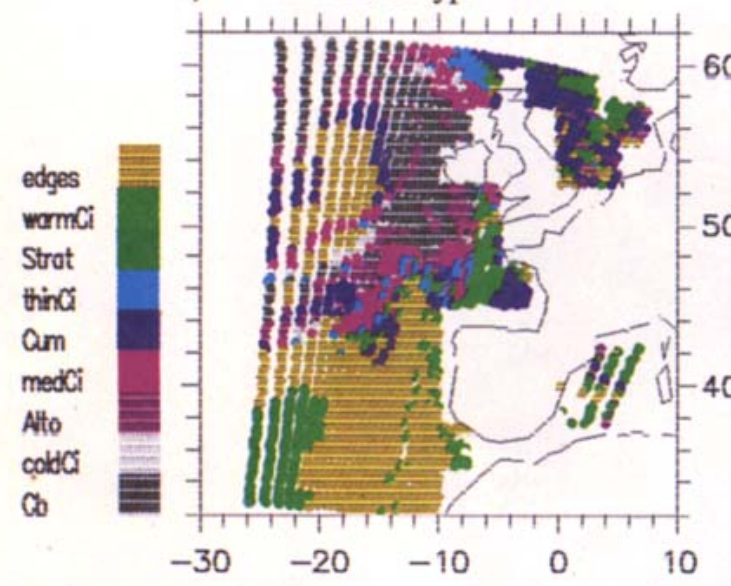

d) Clustering cloud fields,

$\mathrm{T}_{\mathrm{IR}^{-}} \mathrm{T}_{\text {surf }}, 0.01 * \mathrm{~T}_{\mathrm{IR}} * \ln \left(1+\sigma_{3 \times 3 \mathrm{ERBE}}\right)$

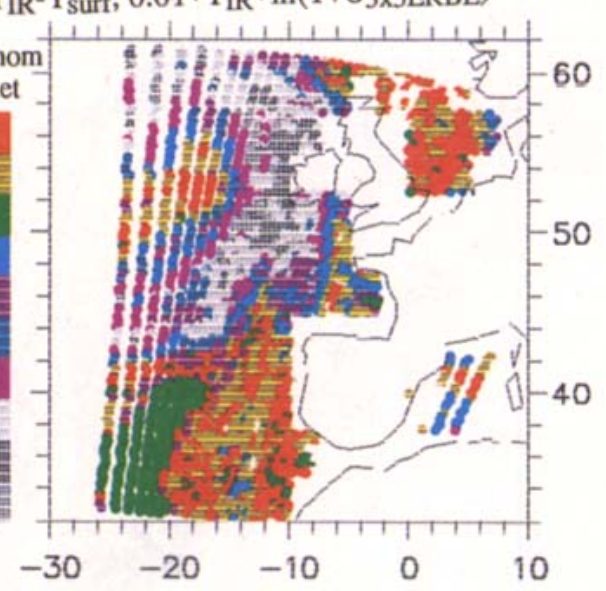

e) Clustering cloud fields,

$\mathrm{T}_{\mathrm{IR}}-\mathrm{T}_{\text {surf }}, 0.01 * \mathrm{~T}_{\mathrm{IR}} * \ln \left(1+\sigma_{3 \times 3 \mathrm{ERBE}}\right), \mathrm{T}(11 \mu \mathrm{m})-\mathrm{T}(12 \mu \mathrm{m})$

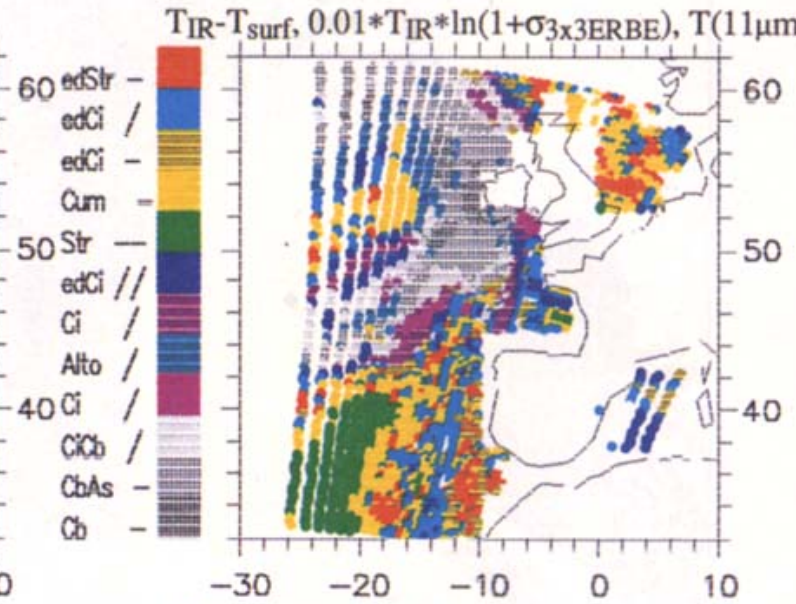

f) Clustering cloud fields,

$\mathrm{T}_{\mathrm{IR}}-\mathrm{T}_{\text {surf }}, 0.01 * \mathrm{~T}_{\mathrm{IR}} * \ln \left(1+\sigma_{3 \times 3 \mathrm{ERBE}}\right), \mathrm{A}^{\text {meas-Amodel }}$

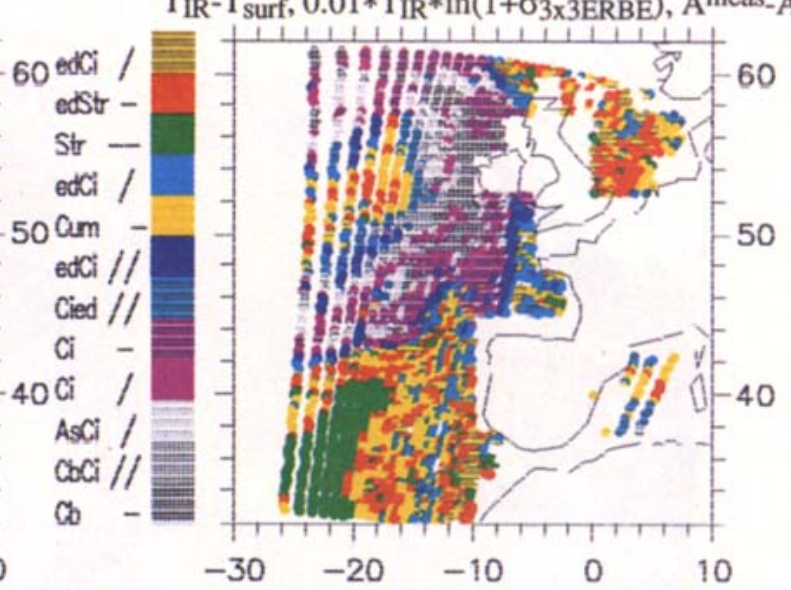

FIG. 3. Satellite data analysis of situation in Fig. 1: (a) ERBE cloud cover; (b) GAC cloud cover; (c) AVHRR cloud type; (d) clustering cloud fields, $T_{\mathrm{IR}}-T_{\text {surf }}$ and $0.01 T_{\mathrm{IR}} \ln \left(1+\sigma_{3 \times 3 \mathrm{ERBE}}\right)$; (e) clustering cloud fields, $T_{\mathrm{IR}}-T_{\text {surf }}, 0.01 T_{\mathrm{IR}} \ln \left(1+\sigma_{3 \times 3 \mathrm{ERBE}}\right)$, and $T(11 \mu \mathrm{m})-T(12$ $\mu \mathrm{m})$; and (f) clustering cloud fields, $T_{\mathrm{IR}}-T_{\mathrm{sur}}, 0.01 T_{\mathrm{IR}} \ln \left(1+\sigma_{3 \times 3 \mathrm{ERBE}}\right)$, and $A^{\text {meas }}-A^{\text {model }}$. The clustering cloud fields are identified by the most frequent AVHRR cloud type within the class. $\mathrm{Cb}$, cumulonimbus; $\mathrm{Ci}$, cirrus; As, Alto; midlevel; Cum, cumulus; Str, stratus; ed, edges. 


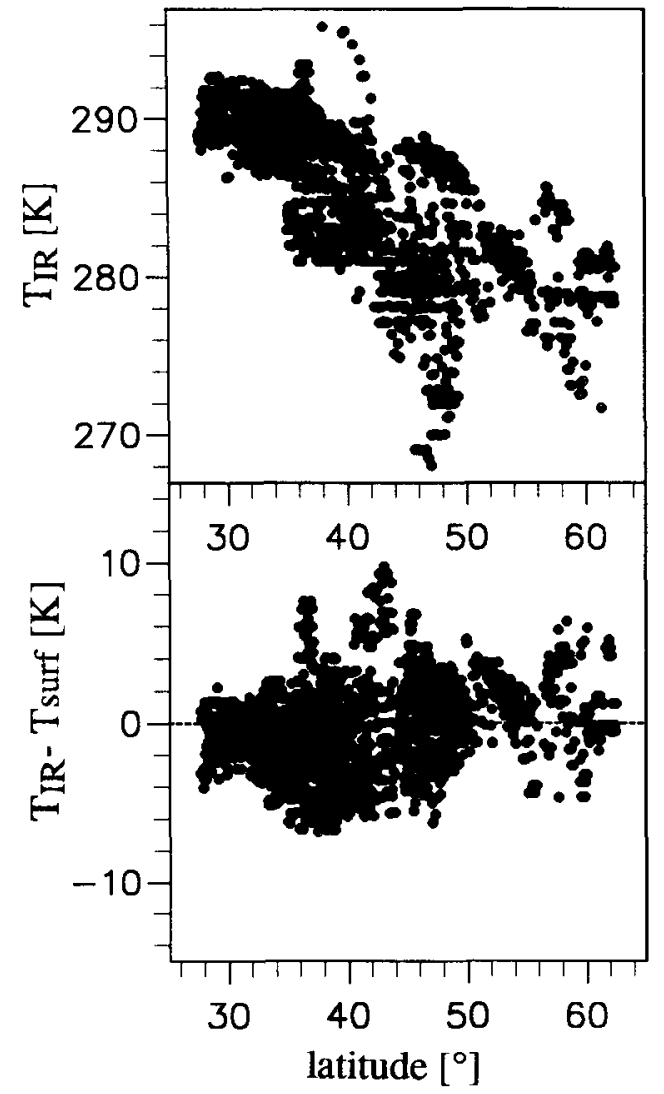

FIG. 4. (a) $T_{\mathrm{IR}}$ and (b) $T_{\mathrm{IR}}-T_{\text {surf }}$ as functions of latitude for clear sky, July 1985 and January 1986.

temperature $T_{\mathrm{IR}}$, one can calculate the emitted broadband LW radiance for the case of no atmospheric absorption. The "atmospheric pseudoabsorptance" has been defined in Stubenrauch et al. (1993) as the normalized difference between the broadband LW radiance, assuming no absorption, and the measured LW radiance $L_{\mathrm{LW}}$ :

$$
\mathrm{A}^{\text {meas }}=1-\frac{L_{\mathrm{LW}}}{\int_{5 \mu \mathrm{m}}^{100 \mu \mathrm{m}} B\left(T_{\mathrm{IR}}\right) d \lambda},
$$

where $B$ is the Planck function.

Note that this term has also been called a "normalized greenhouse effect" (Raval and Ramanathan 1989) in a different context. This quantity is sensitive to the IR brightness temperature and the viewing zenith angle, as can be seen in Fig. 7, which shows $A$ as a function of IR brightness temperature (related to emission height) for different viewing zenith angles calculated with a radiative transfer model (Kneizys et al. 1988) for a midlatitude winter model atmosphere. These calculations have been made only for homogeneous "black" emitting surfaces. To eliminate the temperature correlation, we subtract from the measured and angular corrected $A^{\text {mcas }}$ the pseudoabsorptance $A^{\text {model }}$ at temperature $T_{\mathrm{IR}}$, found by the model for opaque clouds, which we have parameterized as

$$
A^{\text {model }}=\left\{\begin{array}{l}
96.88+0.44 T_{\mathrm{IR}}, \\
\text { for midlatitude winter } \\
-98.30+0.44 T_{\mathrm{IR}}, \\
\text { for midlatitude summer and Tropics. }
\end{array}\right.
$$

The new variable $A^{\text {meas }}-A^{\text {model }}$ should indicate the difference between homogeneous opaque clouds and the measured scene. Indeed, Fig. 8 shows a slight increase of the average $A^{\text {meas }}-A^{\text {model }}$ for cirrus clouds compared to the value for opaque clouds with the same IR temperature, but the distributions are very broad, as the standard deviations indicate. The small difference

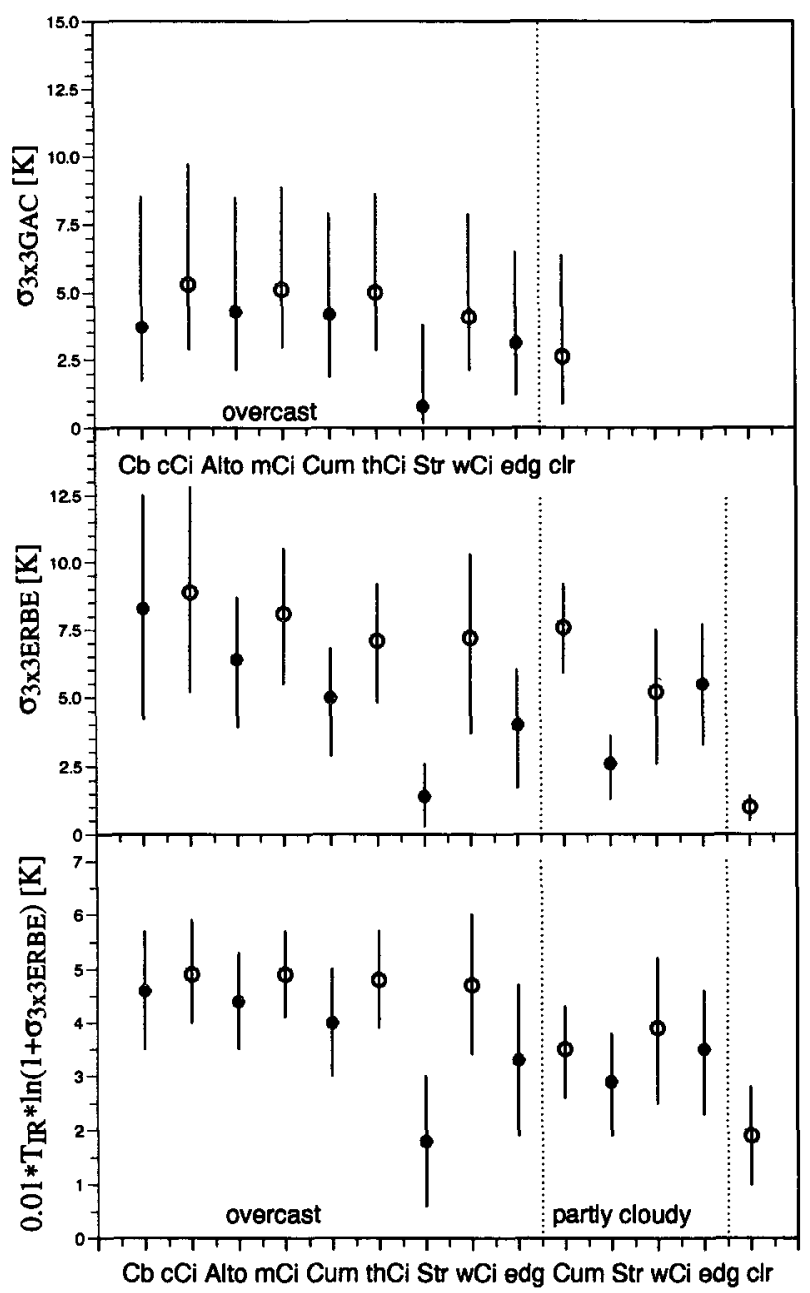

FIG. 5. Spatial resolution effect on temperature variance: (a) average $\sigma_{3 \times 3 \mathrm{GAC}}$ with its standard deviation for 9 AVHRR cloud classes, (b) average $\sigma_{3 \times 3 \mathrm{ERBE}}$ with its standard deviation for 14 AVHRR cloud fields, and (c) average $0.01 T_{\mathrm{IR}} \ln \left(1+\sigma_{3 \times 3 \mathrm{ERBE}}\right)$ with its standard deviation for 14 AVHRR cloud fields. 


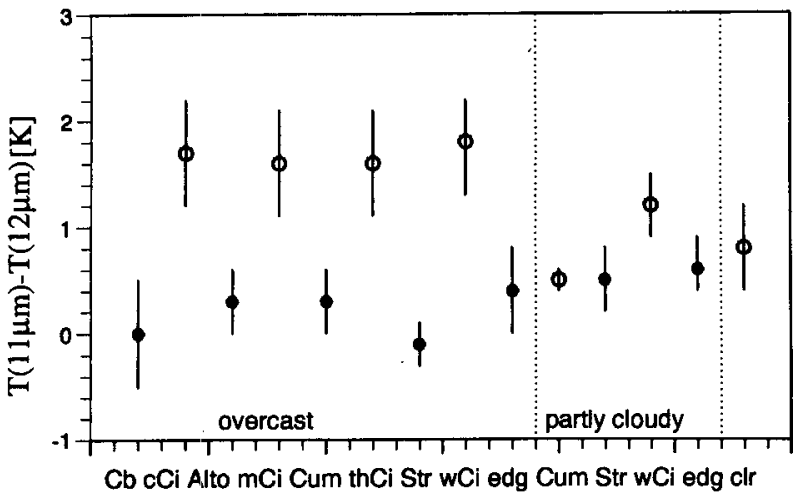

Fig. 6. Average $T(11 \mu \mathrm{m})-T(12 \mu \mathrm{m})$ and its standard deviation for 14 AVHRR cloud fields.

between opaque and cirrus clouds may come from the fact that $T_{\mathrm{IR}}$ describes the "radiative" height of clouds, so the semitransparency of the (in $T_{\mathrm{IR}}$ ) cirrus clouds that appear warmer is taken into account. Therefore, $A^{\text {meas }}$ differs from $A^{\text {model }}$ only due to the larger heterogeneity of cirrus.

\section{Dynamic clustering method}

This clustering method (Diday and Simon 1980) was initially adapted to Meteosat data (Sèze and Desbois 1987). First the $n$ variables to be used are defined and then the data are clustered in the $n$-dimensional space of these variables, each cluster corresponding to a cloud class. To compensate for the different ranges of the variables, different weights are used for each variable. More precisely, in our case, if $\langle x\rangle$ is the mean value and $\sigma_{x}$ is the variance of the variable $x$, it is scaled to $(x-\langle x\rangle) / \sigma_{x}$.

Six nights per month correspond to about 25000 ocean pixels at ERBE resolution. In the first step, one randomly chooses $N F$ points out of the studied data sample and assigns them to $N$ different classes, each containing $F$ pixels representing the kernels of the class. To use most of the data points, we have chosen $N=75$ and $F=300$. Then, the remaining data points are assigned to the class with the nearest center of gravity (according to Euclidean distance in the variable space), taking into account the variance of the kernel. Thus, for each remaining point, one calculates $D=\Sigma(x$ $\left.-\left\langle x_{\text {kernel }}\right\rangle\right)^{2}+\sigma_{\text {kemel }}^{2}$ for all classes and assigns the point to the class corresponding to the minimal $D$. The centers of gravity and variances of the classes are then recalculated, now using all the points.

In the next step, the new kernels are determined by taking $F$ nearest points to the centers of gravity. Then centers of gravity and variances are calculated for these new kernels. One continues the iterations until the distance between the centers of gravity of a class and the corresponding kernel remains constant.

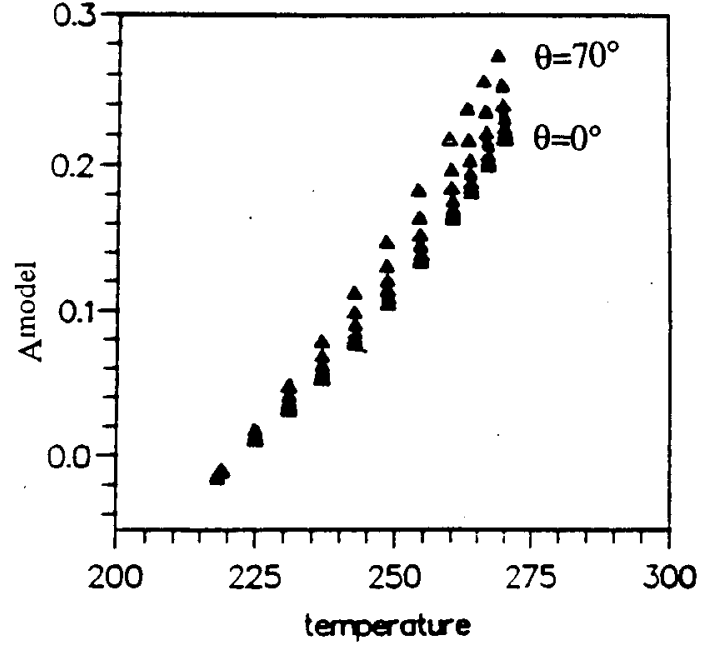

FIG. 7. Atmospheric pseudoabsorptance $A$ as a function of $T_{\mathrm{IR}}$ for opaque homogeneous clouds, calculated by the radiative transfer model LOWTRAN7 for zenith viewing angles $\theta$ between $0^{\circ}$ and $70^{\circ}$.

Once the clear-sky regions are eliminated by the AVHRR threshold test (section 3a), we apply the dynamic clustering method only to cloudy scenes for cloud field classification. We hope to distinguish cloud classes with different height, opacity, and cloud cover. For comparison, we use three different sets of variables in the dynamic clustering method:

1) $T_{\mathrm{IR}}-T_{\text {surf }}$ and $0.01 T_{\mathrm{IR}}\left(1+\sigma_{3 \times 3 \mathrm{ERBE}}\right)$,

2) $T_{\mathrm{IR}}-T_{\text {surf }}, \quad 0.01 T_{\mathrm{IR}}\left(1+\sigma_{3 \times 3 \mathrm{ERBE}}\right)$ and $T(11 \mu \mathrm{m})-T(12 \mu \mathrm{m})$, and

3) $T_{\mathrm{IR}}-T_{\text {surf }}, \quad 0.01 T_{\mathrm{IR}}\left(1+\sigma_{3 \times 3 \mathrm{ERBE}}\right)$ and $A^{\text {meas }}-A^{\text {model }}$.

In January, the clustering yields 14-16 classes. When two classes are very close, a new kernel is defined by merging these two classes and reapplying the dynamical clustering. Eventually, 10 cloud field classes have been determined by using two variables, whereas

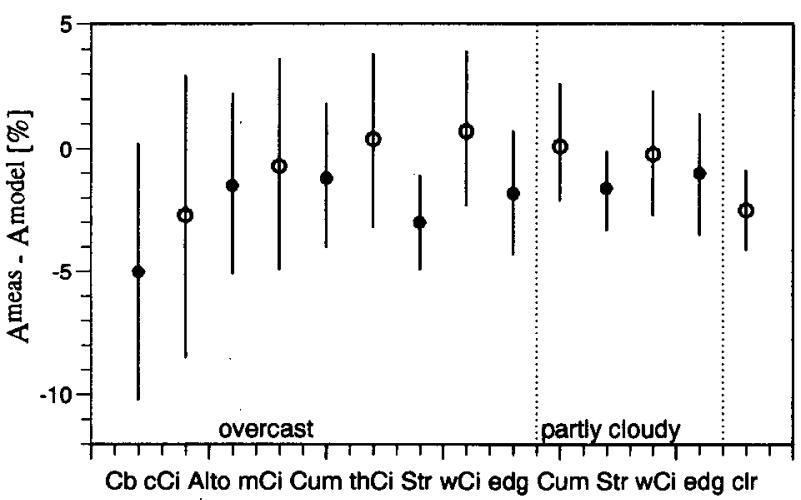

FIG. 8. Average $A^{\text {meas }}-A^{\text {model }}$ and its standard deviation for 14 AVHRR cloud fields. 
$\mathrm{T}_{\mathrm{IR}}-\mathrm{T}_{\text {surf }}[\mathrm{K}] \quad 0.01 \mathrm{~T}_{\mathrm{R}} \ln \left(1+\sigma_{3 \times 3 \mathrm{ERBE}}[\mathrm{K}] \quad\right.$ GACcloud cover [\%] GAC cirrus amount [\%] 3I cloudtop pressire [hPa]
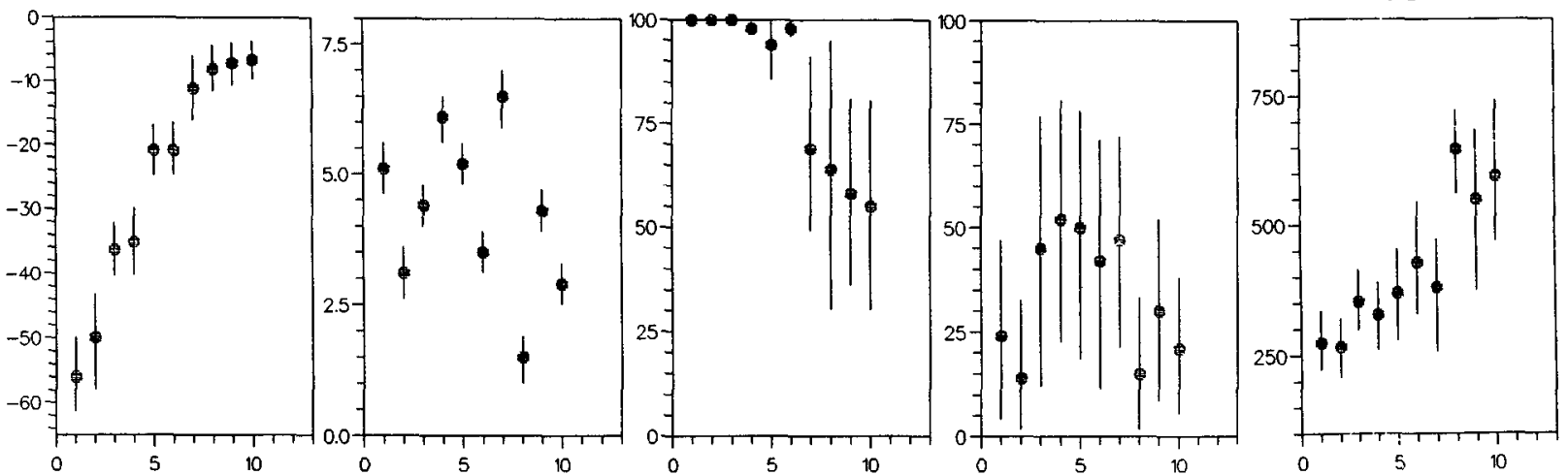

a) 10 cloud fields with $\mathrm{T}_{\mathrm{IR}}-\mathrm{T}_{\text {surf }}, 0.01 * \mathrm{~T}_{\mathrm{IR}} * \ln \left(1+\sigma_{3 \times 3} \mathrm{ERBE}\right)$
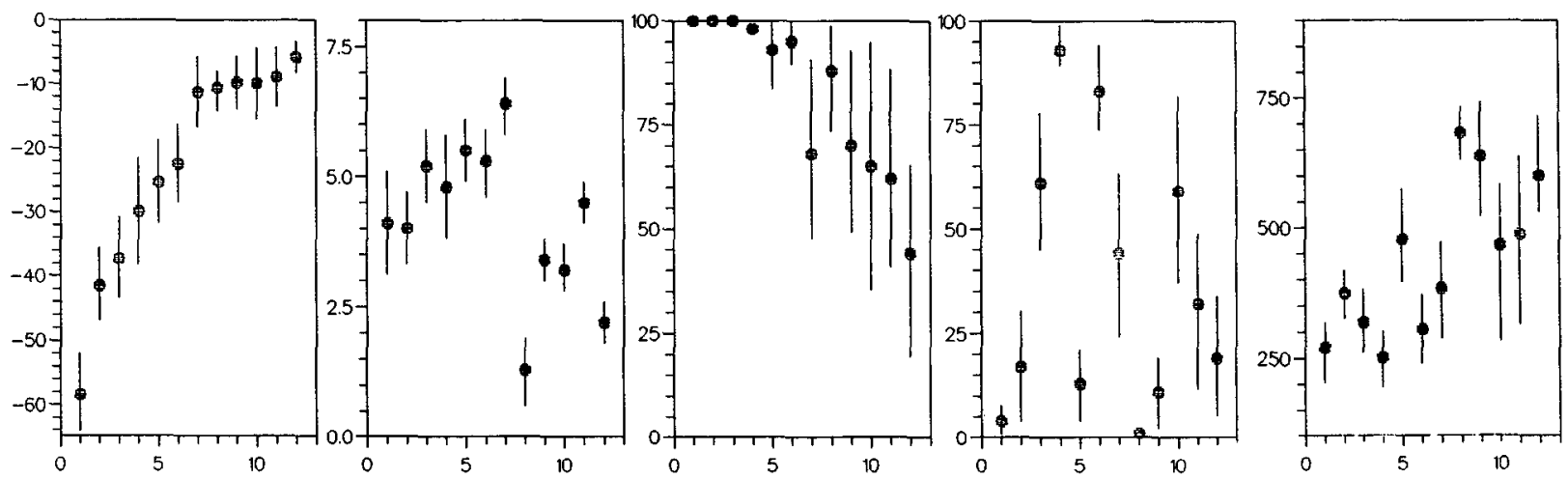

b) 12 cloud fields with $\mathrm{T}_{\mathrm{IR}}-\mathrm{T}_{\text {surf }}, 0.01 * \mathrm{~T} \mathrm{IR} * \ln \left(1+\sigma_{3 \times 3 \mathrm{ERBE}}\right), \mathrm{T}(11 \mu \mathrm{m})-\mathrm{T}(12 \mu \mathrm{m})$
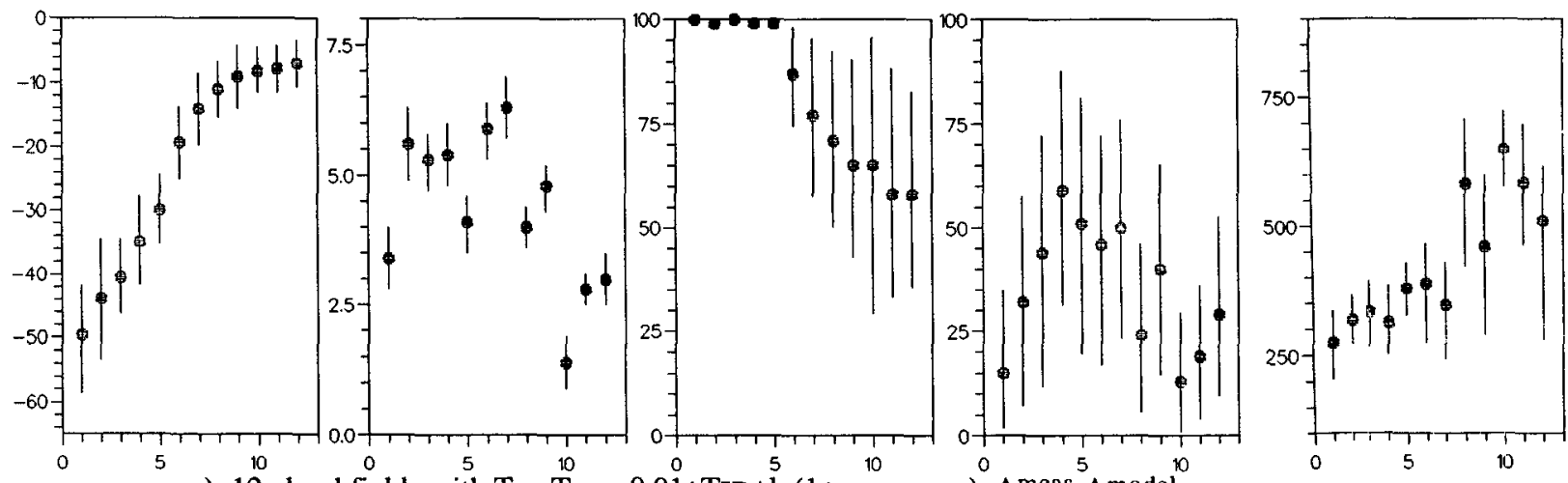

c) 12 cloud fields with $T_{I R}-T_{\text {surf }}, 0.01 * T_{I R} * \ln (1+\sigma 3 \times 3 E R B E)$, A meas-Amodel

FIG. 9. Characteristics of clustering cloud fields: (a) 10 cloud fields with $T_{\mathrm{IR}}-T_{\text {surf }}$ and $0.01 T_{\mathrm{IR}} \ln \left(1+\sigma_{3 \times 3 \mathrm{BRBE}}\right)$ clustering; (b) 12 cloud fields with $T_{\mathrm{IR}}-T_{\text {surf }}, 0.01 T_{\mathrm{IR}} \ln \left(1+\sigma_{3 \times 3 \mathrm{ERBE}}\right)$, and $T(11 \mu \mathrm{m})-T(12 \mu \mathrm{m})$ clustering; and (c) 12 cloud fields with $T_{\mathrm{IR}}-T_{\text {surf }}$ $0.01 T_{\mathrm{IR}} \ln \left(1+\sigma_{3 \times 3 \mathrm{ERBE}}\right)$, and $A^{\text {meas }}-A^{\text {model }}$ clustering.

we are left with 12 cloud field classes when three variables are used.

Figures $3 d-f$ show the three different cloud-fieldtype maps resulting from the clustering method for the meteorological situation of 4 January 1986 . Classes 1 to 10 or 12 are colored from gray (cold) to orange (warm). To give these classes names, we identify each class by the most frequent AVHRR cloud type inside the class. Several classes are a mixture of two or more
AVHRR cloud types. In another column of the picture legends, an indication of the $T_{\mathrm{IR}}$ heterogeneity is given (from analysis of Fig. 9): the symbol "-" denotes homogeneity and " $/$ " denotes heterogeneity. After a first look at these maps, it seems that all sets of variables give good results.

To study more quantitatively the difference between these cloud fields, we consider their mean physical characteristics, such as $T_{\mathrm{IR}}-T_{\mathrm{surf}}, 0.01 T_{\mathrm{IR}} \ln (1$ 
$\left.+\sigma_{3 \times 3 \mathrm{ERBE}}\right)$, GAC cloud cover, AVHRR determined cirrus amount [by $T(11 \mu \mathrm{m})-T(12 \mu \mathrm{m})$ ], and HIRS/ MSU cloud-top pressure (see next section). The averaged quantities with their standard deviations are shown for each cloud field type in Fig. 9, separately for each of the three clusterings.

One observes that by using only two variables, the resulting 10 cloud fields correspond to 5 IR temperatures, each divided into 2 classes of different homogeneity. Six cloud fields (1-6) are overcast and 4 are mostly cloudy (cloud cover varying between $55 \%$ and $70 \%$ ). Five cloud field classes (3-7) with IR temperatures between $-35^{\circ}$ and $-10^{\circ} \mathrm{C}$ have more cirrus clouds (around 50\%) than the others, but the distributions are very wide, leading to the conclusion that a class assigned as cirrus can often be misclassified. By looking at the cloud top pressure one can distinguish 7 cloud fields with high clouds $(1-7), 2$ with midlevel clouds, and 1 with low-level clouds (8).

By using as a third variable, the $T(11 \mu \mathrm{m})-T(12$ $\mu \mathrm{m})$ difference, one improves the separation between opaque and cirrus clouds, as can be seen in the cirrus amount diagram of the second row in Fig. 9. Again, 5 cloud classes are mostly cirrus $(3,4,6,7$, and 10$)$, but this time cirrus amount varies from $50 \%$ to $90 \%$. Half of the classes are overcast $(1-6)$ and the others vary from $45 \%$ to $85 \%$. The cloud-top pressures of these classes reveal 6 high cloud $(1-4,6,7), 3$ mid-high cloud $(5,10,11), 2$ midlevel cloud ( 9 and 12), and 1 low-level cloud class (8).

The third set of variables leads again to 12 classes, in which cirrus and opaque clouds are much less separated than with the second set of variables. The cloud fields are divided into 5 overcast fields $(1-5)$ and 7 partly cloudy fields (between $55 \%$ and $85 \%$ ). Six classes contain mostly cirrus (3-7 and 9) varying between $45 \%$ and $60 \%$. As with the second set of variables, this cloud field classification is largely structured according to cloud height: 7 high cloud (1-7), 2 mid-high cloud (9 and 12), 2 midlevel ( 8 and 11), and 1 low cloud (10) fields. However, the large error bars for midlevel cloud fields imply a possible misidentification for these fields.

\section{Cloud parameters from HIRS-MSU data with 3I algorithm: Comparison with AVHRR cloud types}

To study other geographical regions in which the AVHRR cloud classification that was successfully applied over the North Atlantic does not work, we investigate a cloud field classification obtained from HIRS MSU sounder data.

The 3I algorithm was developed to determine atmospheric temperature, water vapor profiles, and cloud and surface properties (Chedin et al. 1985; Chedin and Scott 1985). This algorithm is based on the archival of a huge dataset of atmospheric profiles (TIGR: thermodynamic initial guess retrieval) from a global set of radiosonde measurements (Escobar 1993). It is also based on radiative transfer calculations simulating clear-sky and cloudy radiances of the 19 HIRS infrared channels and the 4 MSU channels (Scott and Chedin 1981). Clear-sky and cloudy regions are detected at HIRS resolution by a succession of seven (eight) threshold tests at night (day) (Wahiche et al. 1986). This detection relies very much upon the simultaneous use of the HIRS and the MSU channels, the latter of which probes through the clouds. Then the data are merged into $100 \mathrm{~km} \times 100 \mathrm{~km}$ boxes. Temperature inversion and cloud parameter determination are performed at this resolution.

For cloud parameter determination, the radiances of four channels in the $15-\mu \mathrm{m} \mathrm{CO}_{2}$ band and one channel in the $11-\mu \mathrm{m}$ window channel are used. Cloud-top pressure and effective cloud amount are determined by comparing the measured radiances to calculated cloudy and clear-sky radiances at 23 pressure levels for the retrieved atmospheric conditions. A detailed description of the cloud detection algorithm and the recently improved cloud parameter determination can be found in Stubenrauch et al. (1996).

The 3I cloud field classification considers high opaque, cirrus, thin cirrus, midlevel, and low clouds. Each of these cloud types can appear overcast or partly cloudy, leading to 10 different cloud fields. In addition, a partly cloudy cumulus field is defined, with clouds of smaller spatial scale than those of the low-level partly cloudy field.

Three variables govern the classification.

1) Cloud height is given in terms of cloud-top pressure $p_{\text {cld }}$ and the associated cloud-top temperature $T_{\text {cld }}$. The cloud height thresholds have been defined according to the International Satellite Cloud Climatology Project (ISCCP) standard (Rossow and Schiffer 1991): $p_{\text {cld }}<440 \mathrm{hPa}$ for high clouds and $p_{\text {cld }}>680$ $\mathrm{hPa}$ for low clouds. The cloud-top pressure is converted, with the help of the atmospheric profile, to a cloud-top temperature indicating the "real" height of the cloud. The measured $11-\mu \mathrm{m}$ brightness temperature, on the other hand, indicates the "radiative" height of the cloud.

2) Cloud opacity is then correlated to the difference of calculated cloud-top temperature and 11- $\mu \mathrm{m}$ brightness temperature $T_{\text {cld }}-T(11 \mu \mathrm{m})$, since semitransparent cirrus clouds appear warmer at $11 \mu \mathrm{m}$ than opaque clouds at the same altitude. By the same token, when opaque and semitransparent clouds have the same brightness temperature at $11 \mu \mathrm{m}$, the semitransparent clouds are higher. The effective cloud amount alone is not sufficient to distinguish between high opaque and cirrus clouds, because it contains only combined information on cloud thickness and cloud cover.

3) Overcast cloud fields are distinguished from partly covered cloud fields by the effective cloud amount $N \epsilon_{\text {cld }}$. 
The thresholds for this cloud field classification were determined (Stubenrauch et al. 1996) by studying these three variables for the AVHRR cloud fields.

Figures $10 \mathrm{a}, \mathrm{b}$ represent cloud type and cloud cover as obtained by the $3 \mathrm{I}$ algorithm at $100-\mathrm{km}$ resolution for the meteorological situation shown in Fig. 2. In spite of the coarser resolution, strong agreement is seen with the IR image of Fig. 2 as well as with the AVHRR classification in Fig. 3. Pixels characterized as edges by AVHRR, which appear frequently, are even more precisely identified by the 3I classification as midlevel or low-level clouds. In addition, the region between the high opaque clouds and the low-level overcast cloud field, which was identified as having overcast edges by AVHRR, seems to be more clearly determined as partly cloudy by the 3I classification. Since different atmospheric and surface conditions are taken into account in the 3I algorithm, this algorithm and cloud field classification can be applied over the whole globe.

\section{Cloud influence on outgoing $L W$ fluxes}

In the following, we study the emitted LW flux $F_{\mathrm{LW}}$ as a function of cloud-top temperature $T_{\text {cld }}$ for different cloud fields. The emitted LW flux is measured by ERBE, whereas the cloud-top temperature is determined by the 3I algorithm. Figure 11a shows $F_{\mathrm{LW}}$ as a function of $T_{\text {cld }}$ for the nine overcast AVHRR cloud fields. [This figure differs slightly from Fig. 6a in Stubenrauch et al. (1996), because here overcast AVHRR cloud fields are defined with a cloud cover higher than $80 \%$, whereas Stubenrauch et al. (1996) had a more strict definition of higher than $90 \%$.] The broken line represents the theoretically emitted $\mathrm{LW}$ flux corrected for the absorption of the atmosphere $\left[\sigma_{B} T^{4}-A\left(T_{\mathrm{IR}}\right) F_{\mathrm{LW}}\right]$. While the outgoing LW flux is well represented by the theoretical curve for high, midlevel, and low opaque clouds at a given cloud-top temperature, the emitted LW flux is higher for partially covering cloud types such as cumulus, edges, and especially the different cirrus clouds. The dataset reveals clearly that cirrus clouds have a smaller warming effect than high opaque or even midlevel opaque clouds during night.

Figure $11 \mathrm{~b}$ shows $F_{\mathrm{LW}}$ as a function of cloud field temperature $T_{\text {field }}$ for the 11 3I cloud fields. Cloudtop temperature and cloud field temperature are the same for overcast cloud fields. In the case of partial cloud cover, the scene is better described by the cloud field temperature, which is higher than the cloud-top temperature (because part of the earth's surface appears). Since the cloud top and surface radiances add up linearly when weighted by the (apparent) cloud cover, the cloud field temperature can be calculated from the 3I cloud-top temperature $T_{\text {cld }}$, ECMWF surface temperature $T_{\text {surf }}$ [Eq. (1)], and GAC cloud cover (cov) as

$$
T_{\text {field }}=\left[\operatorname{cov} T_{\text {cld }}^{4}+(1-\operatorname{cov}) T_{\text {surf }}^{4}\right]^{1 / 4} .
$$

a) 3I cloud type

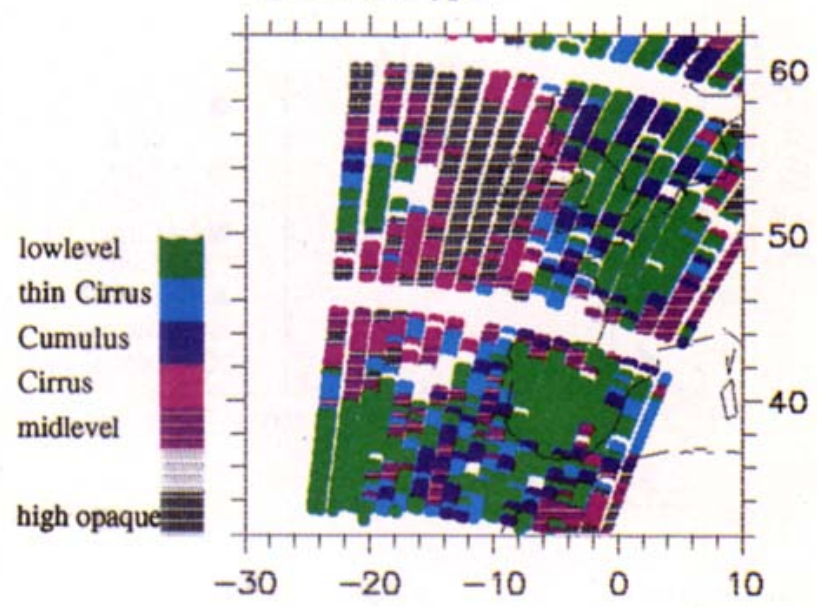

b) 3I cloud cover

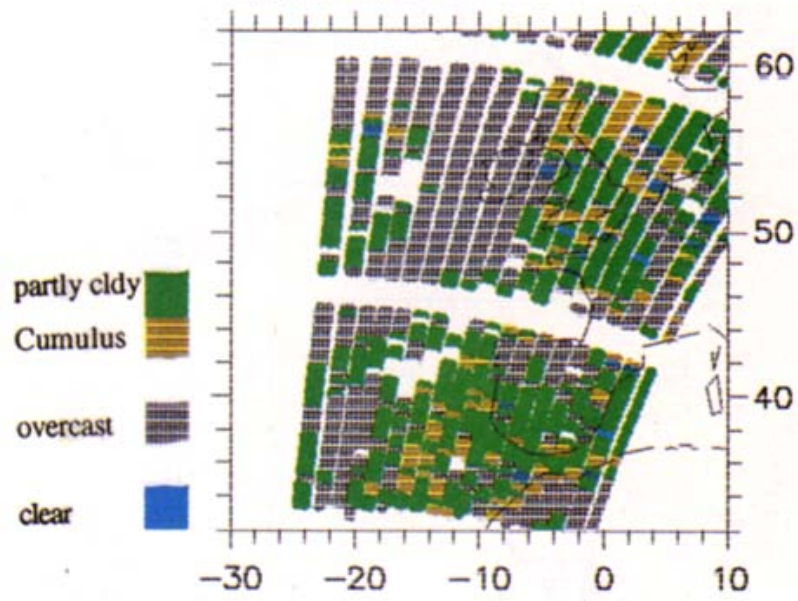

c) 3 I cloud field type

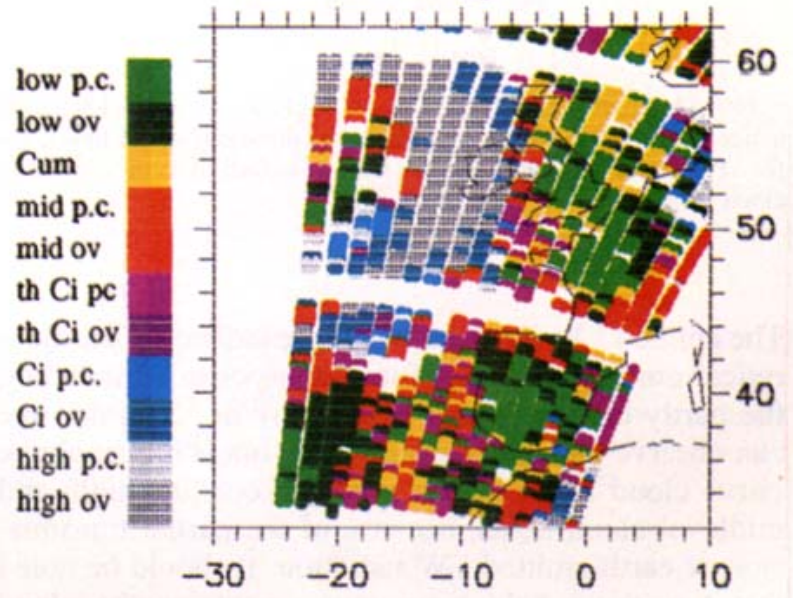

FIG. 10. Satellite data analysis of situation in Fig. 2: (a) 3I cloud type, (b) 3 I cloud cover, and (c) $3 I$ cloud field type. 

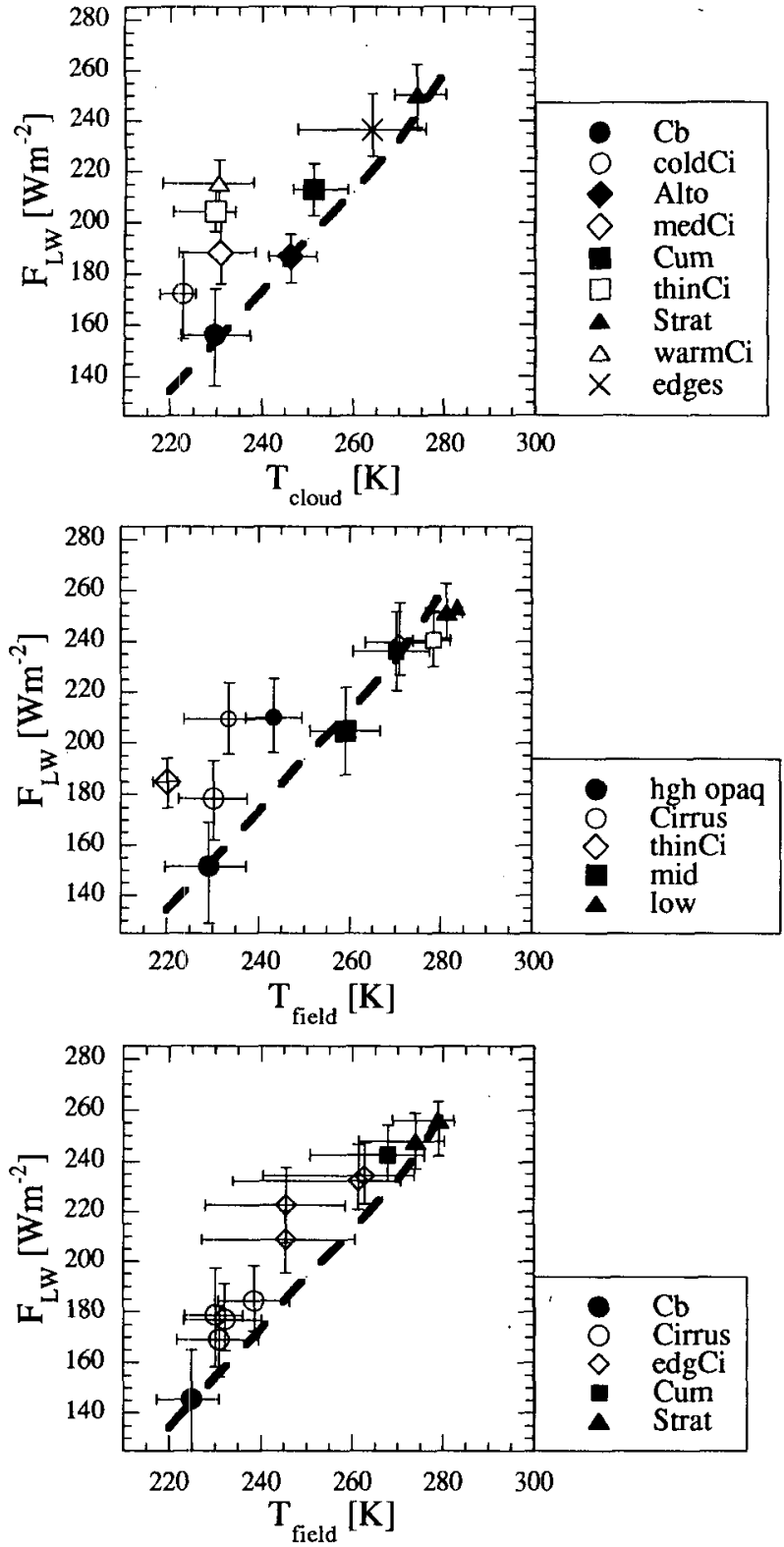

FIG. 11. Emitted LW flux as function of cloud top or cloud field temperature: (a) for 9 overcast AVHRR threshold cloud fields, (b) for $113 \mathrm{I}$ cloud field types, and (c) for $12 \mathrm{ScaRaB}$ dynamic clustering cloud field types.

The emitted LW flux can then be described by the theoretical emitted LW flux for opaque clouds, including the partly cloudy ones within $10 \mathrm{~W} \mathrm{~m}^{-2}$. Again, one can observe that the emerging $\mathrm{LW}$ flux is higher above cirrus cloud fields than it is above opaque, high, and midlevel cloud fields, because of the partial transmission of earth-emitted LW radiation. It should be noted that the cloud field temperature contains the cloud cover, whereas the scene temperature [defined in Stubenrauch et al. (1996), Eq. (4)] contains the effective cloud amount. When the effective cloud amount is included, the emitted LW flux can be described by one theoretical expression for all cloud fields, whereas the theoretical expression works only for opaque clouds when the cloud cover is included in the pixel temperature.

In Fig. 11c, one can see $F_{\mathrm{Lw}}$ as a function of $T_{\text {field }}$ for the 12 cloud fields obtained from the clustering method using the $\mathrm{ScaRaB}$ variables $\left[T_{\mathrm{IR}}-T_{\text {surf }}\right.$, $0.01 T_{\mathrm{IR}}\left(1+\sigma_{3 \times 3 \mathrm{ERBE}}\right)$ and $\left.A^{\text {meas }}-A^{\text {model }}\right]$. While one can easily see from the AVHRR cloud field types and the 3I cloud field types that semitransparent cirrus clouds have a smaller heating effect than high opaque clouds during night, there is much less distinction between the different ScaRaB cloud field types. In particular, the cloud field temperature is determined badly (large error bars) for several cloud field classes, implying the possibility of poorly defined or misidentified classes.

From Fig. 11 we conclude that if one wants to study cloud radiative effects in detail, one should use collocated sounding ERB or imager ERB data. On the other hand, one could define some cloud field types with ScaRaB data in order to get an initial impression of the cloud situation over the globe. For this purpose, distributions of the best-suited variables for a ScaRaB cloud field classification, as determined in section 4 , are studied in the next section for the different 3I cloud field types.

\section{Investigating another cloud field classification method in comparison to 3 I cloud fields}

By using the dynamical clustering method, one can detect different cloud fields without any a priori knowledge, although it is difficult to assign names to the clustering cloud field types. On the other hand, the 3I cloud field classification can serve as a reference on a global scale for a cloud field classification using ScaRaB data. Then one can determine the mean values of the three quantities $T_{\mathrm{IR}}-T_{\text {surf }}, 0.01 T_{\mathrm{IR}} \ln \left(1+\sigma_{3 \times 3 \mathrm{ERBE}}\right)$, and $A^{\text {meas }}-A^{\text {model }}$ for the $113 \mathrm{I}$ cloud fields and use these as the kernel mean values for the clustering method. In this case, when the kernels of the classes are determined in advance, the clustering method reduces to an MLE method. Here, kernels have to be found for different seasons and geographical regions.

The average values and standard deviations of the quantities $T_{\mathrm{IR}}-T_{\text {surf }}$ and $0.01 T_{\mathrm{IR}} \ln \left(1+\sigma_{3 \times 3 \mathrm{ERBE}}\right)$ are represented as a two-dimensional plot in Fig. 12a for the 11 3I cloud field types. To study the change of mean values with season and geographical region, we look at four means for each 3I cloud field type: July and January over the North Atlantic and the tropical Atlantic. Since these variables overlap between several cloud fields, it is certainly not possible to detect as many as 11 different cloud field types with the $\mathrm{ScaRaB}$ instrument. Examination of Fig. 12b (in which averaged val- 

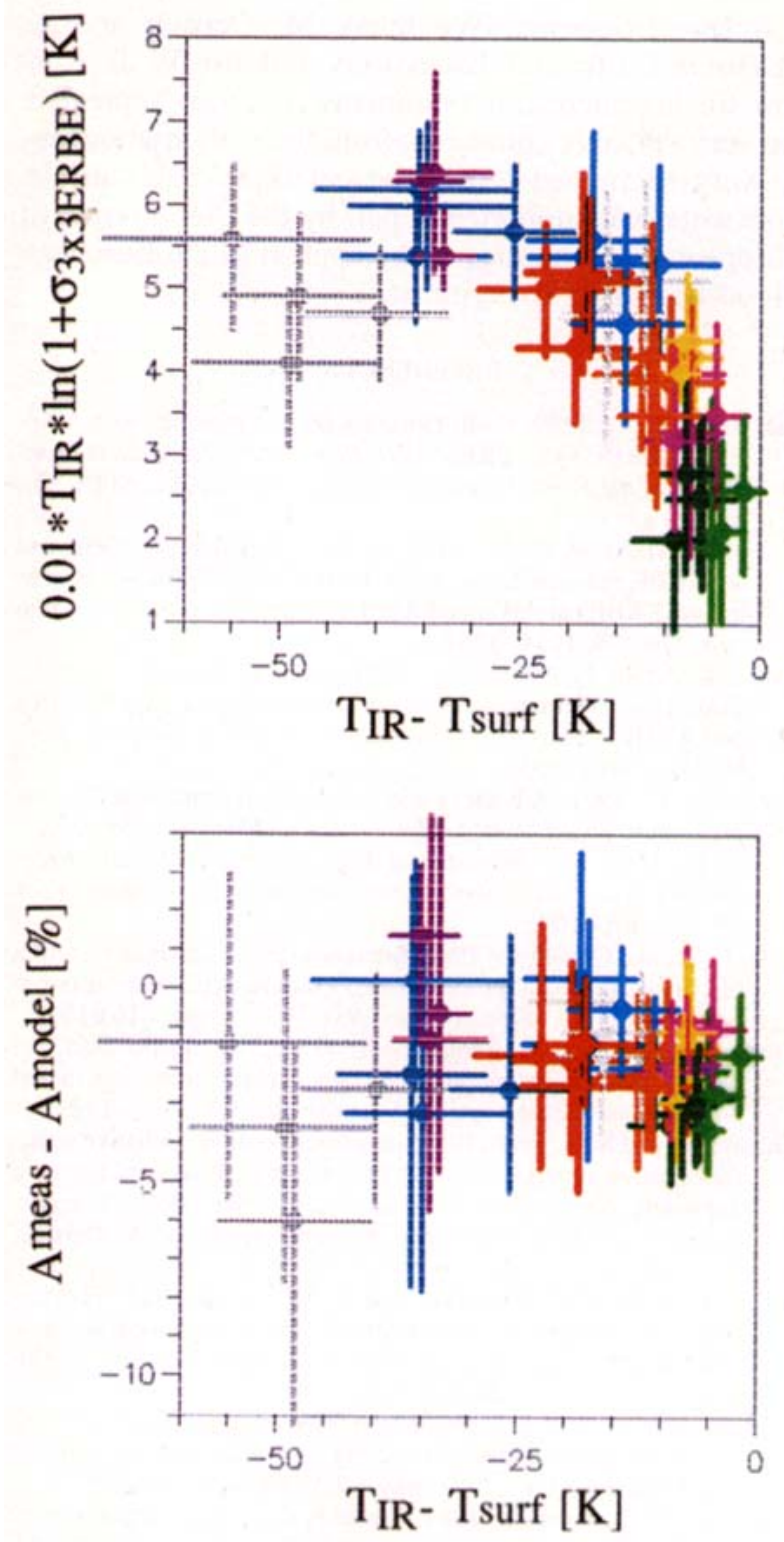

FIG. 12. Characteristics of 3I cloud fields, in July and January in the North Atlantic and tropical Atlantic (a) averaged $T_{\mathrm{IR}}-T_{\text {surf }}$ and $0.01 T_{\mathrm{IR}} \ln \left(1+\sigma_{3 \times 3 \mathrm{ERBE}}\right)$ with variances for $113 \mathrm{I}$ cloud field types, and (b) averaged $T_{\mathrm{IR}}-T_{\mathrm{surf}}$ and $A^{\text {meas }}-A^{\text {model }}$ with variances for 11 3I cloud field types.

ues of $T_{\mathrm{IR}}-T_{\text {surf }}$ and $A^{\text {meas }}-A^{\text {model }}$ are plotted with their standard deviations ) for the 11 3I cloud field types again shows that $A^{\text {meas }}-A^{\text {model }}$ should enhance the distinction between cloud field classes, even when the distribution of this variable is much broader and dependent upon season and region. These two diagrams help us to determine different kernel mean values of the three variables in order to distinguish between several cloud field classes.

We conclude that during nighttime it should be possible to discriminate between about seven cloud field types using ScaRaB LW and IR window measurements alone. After chosing seven kernel mean values of the three variables in Fig. 12, a simple MLE algorithm is applied to the North Atlantic data. These cloud field types [with their corresponding kernels in $T_{\mathrm{IR}}-T_{\text {surf }}$, $0.01 T_{\mathrm{IR}} \ln \left(1+\sigma_{3 \times 3 \mathrm{ERBE}}\right)$, and $A^{\text {meas }}-A^{\text {model }}$ ] are high opaque overcast $\left(-45^{\circ} \mathrm{C}, 5^{\circ} \mathrm{C},-4 \%\right)$, cirrus overcast $\left(-35^{\circ} \mathrm{C}, 6^{\circ} \mathrm{C}, 0 \%\right)$, midlevel overcast $\left(-25^{\circ} \mathrm{C}, 5^{\circ} \mathrm{C}\right.$, $-2.5 \%)$, high partly cloudy $\left(-20^{\circ} \mathrm{C}, 5.5^{\circ} \mathrm{C},-1 \%\right)$, midlevel partly cloudy $\left(-10^{\circ} \mathrm{C}, 4^{\circ} \mathrm{C},-1 \%\right)$, low overcast $\left(-8^{\circ} \mathrm{C}, 1.5^{\circ} \mathrm{C},-3 \%\right)$, and low partly cloudy $\left(-5^{\circ} \mathrm{C}, 2.5^{\circ} \mathrm{C},-2 \%\right)$.

The ScaRaB cloud field map, shown in Fig. 13, shows an encouraging result. From this map it is clear that with ScaRaB data alone it is possible to give a rough description of the meteorological situation. However, the outgoing LW flux distributions of these different cloud field types are much too broad for differences between opaque and semitransparent cloud fields to be distinguished. (Fig. 14).

\section{Summary and conclusions}

At the coarse spatial resolution of ERB observations, it is still possible to identify cloud fields according to cloud height, opacity, and cloud cover, but only by using sounding data, which has good spectral resolution. Three cloud heights, three opacities, and two cloud covers (overcast and partly cloudy) can be distinguished. Hence, by combining ERB broadband radiance measurements from ERB experiments (such as ERBE, ScaRaB, or later on CERES ) with cloud field classification from sounding instruments (such as the 3I cloud algorithm applied on HIRS/MSU), one can distinguish the cloud-induced radiative flux change of different cloud field types. It is very interesting to compare these cloud-induced flux changes to those calculated in general circulation model climate simulations.

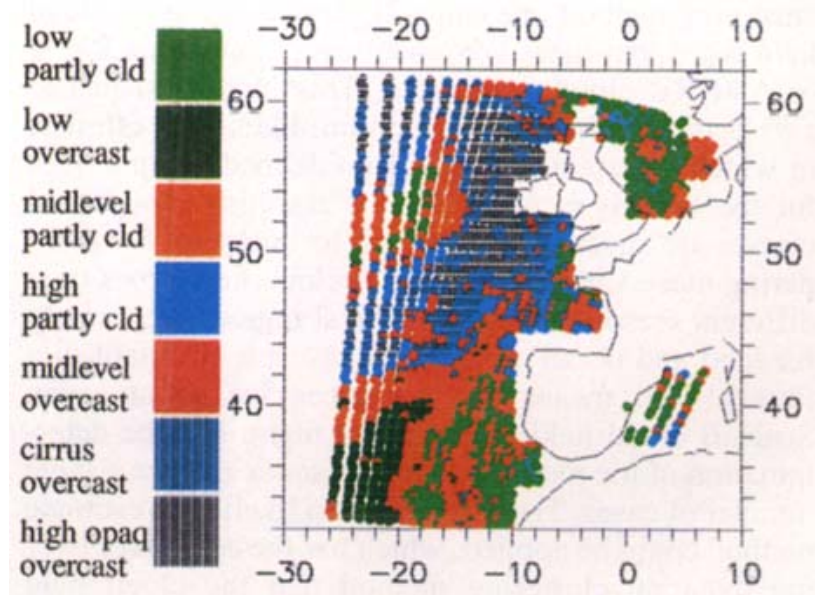

FIG. 13. Satellite data analysis of situation in Fig. 2: 7 ScaRaB MLE cloud field types. 


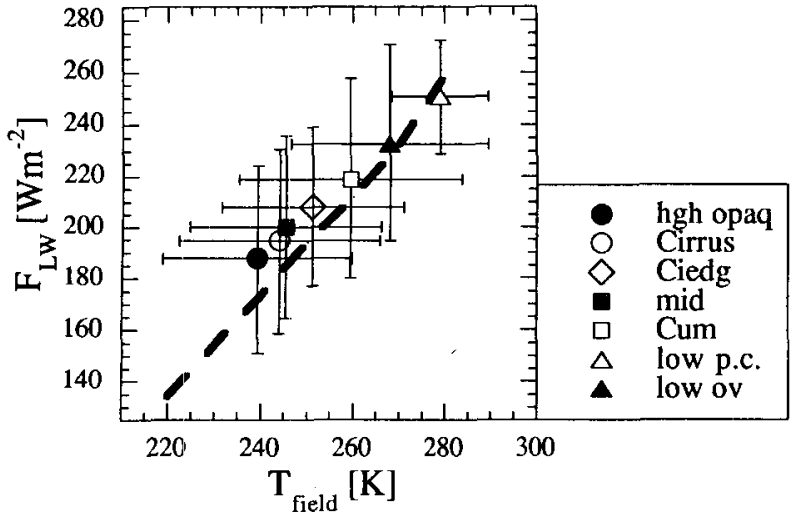

FIG. 14. Emitted LW flux as a function of cloud field temperature for seven ScaRaB MLE cloud field types: hgh opaq, high opaque overcast; cirrus, cirrus overcast; Ciedg: high partly cloudy; mid, midlevel overcast; Cum, midlevel partly cloudy; low p.c., low partly cloudy; low ov, low overcast.

In this study we simulated ScaRaB data by collocating broadband ERBE measurements with narrowband AVHRR measurements. It was shown that with ScaRaB data alone one could define roughly about seven cloud field types during nighttime (high opaque overcast, cirrus overcast, midlevel overcast, high partly cloudy, midlevel partly cloudy, low overcast, and low partly cloudy), yielding an initial impression of the cloud situation over the globe and allowing the calculation of SW angular corrections for these different cloud fields. From the variables available during night, the difference between IR window brightness temperature and surface air temperature $T_{\mathrm{IR}}-T_{\text {surf }}$ and the scaled IR temperature variance $0.01 T_{\mathrm{IR}} \ln \left(1+\sigma_{3 \times 3}\right)$ over nine $\mathrm{ScaRaB}$ pixels is the best suited for global cloud field identification. A third variable combining narrowband and broadband $\mathrm{LW}$ measurements $A^{\text {meas }}$ $-A^{\text {model }}$ could slightly enhance the distinction between high opaque and semitransparent cirrus clouds, but this variable creates large uncertainties. With the dynamic clustering method one can still identify about 11 cloud field types, but these are much less distinct than the 3I or AVHRR cloud field types. This method seems to give better results than a maximum-likelihood estimate in which a certain number of predefined mean values for the kernels is used, but the resulting cloud field classes are much more difficult to interpret. By comparing these variables for the 3I cloud field types over different seasons and geographical regions (separately for land and ocean), it may be possible to establish a library with means and variances for about seven ScaRaB cloud field types during night. For the determination of the means it is important to analyze a large number of cases. Then, a maximum likelihood estimate method could be applied, which has the advantage over the dynamic clustering method that the cloud field types are the same for all seasons and regions and hence easier to interpret.
Acknowledgments. We thank M. Derrien and A. Marsouin for fruitful discussions, and also W. B. Rossow for his interesting comments. We also appreciate the very valuable comments from three anonymous reviewers that helped us to shape and improve this article. This work was supported in part by the Commission of European Communities in the context of the European Cloud-Radiation Experiment.

\section{REFERENCES}

Barkstrom, B. R., 1990: Earth radiation budget measurements: PreERBE, ERBE and CERES, SPIE Proc. 12999 Long-Term Monitoring of the Earth's Radiation Budget, Orlando, FL, SPIE, 5260.

, E. F. Harrison, G. L. Smith, R. Green, J. Kibler, R. Cess, and the ERBE Science Team, 1989: Earth Radiation Budget Experiment (ERBE) archival and April 1985 results. Bull. Amer. Meteor. Soc., 70, 1254-1262.

Baum, B. A., R. F. Arduini, B. A. Wielicki, P. Minnis, and S.-C. Tsay, 1994: Multilevel cloud retrieval using multispectral HIRS and AVHRR data: Nighttime oceanic results. J. Geophys. Res., 99(D3), 5499-5514.

Bengtsson, L., 1991: Advances and prospects in numerical weather prediction. Quart. J. Roy. Meteor. Soc., 117(501), 855-902.

Berger, F., 1992: The influence of high clouds on climate. Proc. Central Symp. on Int. Space Year Conf., Munich, Germany, ESA SP-341, 105-109.

Cess, R. D., and Coauthors, 1990: Intercomparison and interpretation of climate feedback processes in 19 atmospheric general circulation models. J. Geophys. Res., 95(D10), 16 601-16 615.

Charlock, T. P., and V. Ramanathan, 1985: The albedo field and cloud radiative forcing produced by a general circulation model with internally cloud optics. J. Atmos. Sci., 42, 1408-1429.

Chedin, A., and N. A. Scott, 1985: Initialization of the radiative transfer equation inversion problem from a pattern recognition type approach: Application to the satellites of the TIROS-N series. Advances in Remote Sensing Retrieval Methods, A. Deepak, 495-515.

, N. A. Scott, C. Wahiche, and P. Moulinier, 1985: The improved initialized inversion method: A high resolution physical method for temperature retrievals from Tiros-N series. $\mathrm{J}$. Climate Appl. Meteor., 24, 124-143.

Coakley, J. A., Jr., and F. P. Bretherton, 1982: Cloud cover from high resolution scanner data: Detecting and allowing for partially filled fields of view. J. Geophys. Res., 87, 4917-4932.

- and D. G. Baldwin, 1984: Towards the objective analysis of clouds from satellite imagery data. J. Climate Appl. Meteor., 23, 1065- 1099 .

Derrien, M., B. Farki, L. Harang, H. Le Gléau, A. Noyalet, D. Pochie, and A. Sairouni, 1993: Automatic cloud detection applied to NOAA-II AVHRR imagery. Remote Sens. Environ., 46, 246 267.

Diday, E., and J. C. Simon, 1980: Clustering analysis. Digital Pattern Recognition, K. S. Fu, Ed., Springer Verlag, 47-94.

Escobar, J., 1993: Base de données pour restitution de paramètres atmosphériques à l'échelle globale, Etude sur l'inversion par réseaux de neurones de données des sondeurs verticaux atmosphériques satellitaires présents et à venir, Ph.D. dissertation, Univ. Pierre et Marie Curie, 167 pp. [Available from LMD, Ecole Polytechnique, 91128 Palaiseau cedex, France].

Harrison, E. F., P. Minnis, B. R. Barkstrom, V. Ramanathan, R. D. Cess, and G. G. Gibson, 1990: Seasonal variation of cloud radiative forcing derived from the Earth Radiation Budget Experiment. J. Geophys. Res., 95(D11), $18687-18703$.

Kneizys, F. X., E. P. Shettle, L. W. Abrieu, J. H. Chetwynd, G. P. Anderson, W. O. Gallery, J. E. A. Selby, and S. A. Clough, 1988: Users Guide to LOWTRAN7, AFGL-TR-88-0177. [Available from AFGL (OPI), Hanscom AFB, MA.] 
Kriebel, K. T., and R. W. Saunders, 1988: An improved method for detecting clear sky and cloudy radiances from AVHRR data. Int. J. Remote Sens., 9, 123-150.

Llewellyn-Jones, D. T., P. J. Minnett, R. W. Saunders, and A. M. Zavody, 1984: Satellite multichannel infrared measurements of sea surface temperature of the N.E. Atlantic Ocean using AVHRR/2. Quart. J. Roy. Meteor. Soc., 110, 613-631.

Monge, J. L., R. S. Kandel, L. A. Pakhomov, and V. I. Adasko, 1991: ScaRaB earth radiation budget scanning radiometer. Metrologia, 28, 261-264.

Ockert-Bell, M. E., and D. L. Hartmann, 1992: The effect of cloud type on earth's energy balance: Results for selected regions. $J$. Climate, 5, 1157-1171.

Prabhakara, C., R. S. Fraser, G. Dalu, C. Wu Man-Li, and R. J. Curran, 1988: Thin cirrus clouds: Seasonal distribution over oceans deduced from Nimbus-4 IRIS. J. Appl. Meteor., 27, 379-399.

Raval, A., and V. Ramanathan, 1989: Observational determination of the Greenhouse Effect. Nature, 342, 758-761.

Rossow, W. B., and R. A. Schiffer, 1991: ISCCP cloud data products. Bull. Amer. Meteor. Soc., 72, 1-20.

-, and L. C. Garder, 1993: Cloud detection using satellite measurements of infrared and visible radiances for ISCCP. J. Climate, 6, 2341-2369.

- and Coauthors, 1985: ISCCP cloud algorithm intercomparison. J. Climate Appl. Meteor., 24, 877-903.

Scott, N. A., and A. Chedin, 1981: A fast line-by-line method for atmospheric absorption computations: The automized atmospheric absorption atlas. J. Appl. Meteor., 20, 802-812.

Sèze, G., and M. Desbois, 1987: Cloud cover analysis from satellite imagery using spatial and temporal characteristics of the data. J. Climate Appl. Meteor., 26, 287-303.
Slingo, A., and J. M. Slingo, 1991: Response of the National Center for Atmospheric Research Community Climate Model to improvements in the representation of clouds. J. Geophys. Res., 96(8), $15341-15337$.

Stowe, L. L., E. P. McClain, R. Carey, P. Pellegrino, G. G. Gutman, P. Davis, C. Long, S. Hart, 1991: Global distribution of cloud cover derived from NOAA/AVHRR operational satellite data. Adv. Space Res., 11, 351-354.

Stubenrauch, C., 1993: Co-location of AVHRR, ERBE and HIRS/ MSU data. Internal Note no 185, Laboratoire de Météorologie Dynamique, 9 pp. [Available from LMD, Ecole Polytechnique, 91128 Palaiseau, Cedex, France.]

_ J.-Ph. Duvel, and R. S. Kandel, 1993: Determination of longwave anisotropic emission factors from combined broad- and narrowband radiance measurements. J. Appl. Meteor., 32, 848856.

- N. A. Scott, and A. Chedin, 1996: Cloud field identification for earth radiation budget studies. Part I: Cloud field classification using HIRS-MSU sounder measurements. J. Appl. Meteor., 35, 416-427.

Susskind, J., D. Reuter, and M. T. Chahine, 1987: Cloud fields retrieved from analysis of HIRS2/MSU sounding data. J. Geophys. Res., 92(D4), 4035-4050.

Wahiche, C., N. A. Scott, and A. Chedin, 1986: Cloud detection and cloud parameters retrieval from the satellites of the TIROS-N Series. Ann. Geophys., 4B, 207-222.

Wielicki, B. A., and R. N. Green, 1989: Cloud identification for ERBE radiative flux retrieval. J. Appl. Meteor., 28, 11331146.

Wylie, D. P., and W. P. Menzel, 1989: Two years of cloud cover statistics using VAS. J. Climate, 2, 380-392. 